\title{
Consistent assignment of the vibrations of symmetric and asymmetric meta-disubstituted benzenes
}

David J. Kemp, William D. Tuttle, Florence M. S. Jones, Adrian M. Gardner, Anna Andrejeva, Jonathan C. A. Wakefield and Timothy G. Wright ${ }^{\mathrm{a}, *}$

${ }^{a}$ School of Chemistry, University of Nottingham, University Park, Nottingham, NG7 2RD, U.K.

*To whom correspondence should be addressed. Email: Tim.Wright@nottingham.ac.uk 


\section{Abstract}

The assignment of vibrational structure in spectra gives valuable insights into geometric and electronic structure changes upon electronic excitation or ionization; particularly when such information is available for families of molecules. We give a description of the phenyl-ringlocalized vibrational modes of the ground $\left(\mathrm{S}_{0}\right)$ electronic states of sets of meta-disubstituted benzene molecules including both symmetrically- and asymmetrically-substituted cases. As in our earlier work on monosubstituted benzenes [A. M. Gardner and T. G. Wright. J. Chem. Phys. 135 (2011) 114305], para-disubstituted benzenes [A. Andrejeva, A. M. Gardner, W. D. Tuttle, and T. G. Wright, J. Molec. Spectrosc. 321 (2016) 28], and ortho-disubstituted benzenes [W. D. Tuttle, A. M. Gardner, A. Andrejeva, D. J. Kemp, J. C. A. Wakefield and T. G. Wright, J. Molec. Spectrosc. 344 (2018) 46], we conclude that the use of the commonly-used Wilson or Varsányi mode labels, which are based on the vibrational motions of benzene itself, is misleading and ambiguous. Instead, we label the phenyl-ring-localized modes consistently based upon the Mulliken (Herzberg) method for the modes of meta-difluorobenzene ( $\mathrm{mDFB}$ ) under $C_{s}$ symmetry, since we wish the labelling scheme to cover both symmetrically- and asymmetrically-substituted molecules. By studying the vibrational wavenumbers obtained from the same force-field while varying the mass of the substituent, we are able to follow the evolving modes across a wide range of molecules and hence provide consistent assignments. We assign the vibrations of the following sets of molecules: the symmetric metadihalobenzenes, meta-xylene and resorcinol (meta-dihydroxybenzene); and the asymmetric meta-dihalobenzenes, meta-halotoluenes, meta-halophenols and meta-cresol. In the symmetrically-substituted species, we find two pairs of in-phase and out-of-phase carbonsubstituent stretches, and this motion persists in asymmetrically-substituted molecules for heavier substituents; however, when at least one of the substituents is light, then we find that these evolve into localized carbon-substituent stretches.

Keywords: Vibrations; Frequencies; Ground electronic state; meta-Disubstituted Benzenes 


\section{Introduction}

Vibrations are key quantities by which spectroscopists gain insight into both geometric and electronic structures of molecules. Analyzing the vibrational activity during electronic transitions or ionization allows elucidation of resultant changes in geometry and, by looking at the changes in vibrational wavenumber, information on changes in electronic structure can be inferred. For reliable comparison between like-families of molecules one desires the consistent assignment of the spectral lines, in terms of the normal modes of the molecules. Problems arise in these comparisons as even quite small changes in structure can lead to significant changes in the appearance of the spectrum. These changes may be due to a change in the symmetry point group of the molecule, shifts in vibrational wavenumber as a result of mass differences, and electronic effects.

In the present and related work, we have focused particularly on the study of substituted benzenes, where comparison between molecules has often been obfuscated through the use of three different vibrational labelling schemes: the Wilson mode labels [1]; the related Varsányi [2] scheme; and the "Mulliken" [3] (or "Herzberg") labels [4].We have previously discussed these schemes in great detail for monosubstituted benzenes [5], and concluded these were unreliable. Our solution to these problems is highlighted in detail in Ref. [5] for the case of monosubstituted benzenes. It comprised the use of quantum chemical calculations to calculate the force field of benzene and then to artificially increase the mass of a single hydrogen atom stepwise. We found that the variations in wavenumber appeared largely to settle down when the substituent mass reached approximately $15 \mathrm{amu}$, and only small changes in wavenumber were observed for any vibration above this. This then allowed fluorobenzene to be chosen as a sensible basis for the labelling (a substituent of $19 \mathrm{amu}$ ). A notable aspect is that changes in vibrational wavenumbers were apparently not significantly dependent on electronic effects (resonance or inductive).

In a similar way, the vibrational character is expected to change for disubstitutions, which can be viewed as a disubstitution of benzene, or a further substitution of a monosubstituted benzene. In order to have consistent labelling of vibrational motions we have found that it is required to have separate labelling schemes for monosubstituted [5], and para- [6] and orthodisubstituted [7] benzenes. There is a degree of inconvenience in using multiple labelling schemes depending on the benzene isomer; however, this emphasises the point that assuming 
vibrations of different substituted benzenes are the same, as implied by Wilson or Varsányi labels, is misleading.

The labelling scheme for the monosubstituted benzenes has been applied in a series of papers on vibrationally-resolved electronic spectra of jet-cooled monohalobenzenes - see Refs. [8], [9] and [10] - as well as in studies of toluene [11, 12] using zero-kinetic-energy (ZEKE) spectroscopy and two-dimensional laser induced fluorescence [13]; similarly, we have applied the scheme for para-disubstituted benzenes, which can be either symmetrically or asymmetrically disubstituted, in analyzing the vibrational activity following either electronic excitation or ionization in para-fluorotoluene $(p \mathrm{FT})[14,15]$, para-xylene ( $p \mathrm{Xyl})[16,17]$, and para-chlorofluorobenzene ( $p \mathrm{ClFB}$ ) [18]. Through the use of these schemes we have been able to show clearly the high correspondence in vibrational activity between the aforementioned molecules.

Herein, we shall complete our examination of the vibrations of the $S_{0}$ states of disubstituted benzenes by considering different meta-disubstituted benzenes. We shall again conclude that it is not possible to use the Wilson (or Varsányi) labels, nor the Mulliken (or Herzberg) labels consistently. Furthermore, we will conclude that it is not possible to use the monosubstituted, para-nor ortho-disubstituted schemes for meta-disubstituted benzenes. We put forward a new labelling scheme to be used exclusively for meta-disubstituted benzenes, covering both the symmetrically- and asymmetrically-disubstituted molecules. We employ a scheme based upon the lowest common point group shared by the disubstituted benzene family which, in this case, is $C_{s}$ symmetry, and base it on the vibrations of meta-difluorobenzene ( $\left.m \mathrm{DFB}\right)$.

\section{Computational Details}

All harmonic vibrational frequencies were obtained using B3LYP/aug-cc-pVTZ calculations via the GAUSSIAN 09 software package [19]. For bromine and iodine atoms, the full relativistic effective core potentials, ECP10MDF and ECP28MDF respectively, were used with corresponding aug-cc-pVTZ-PP valence basis sets. All calculated harmonic vibrational wavenumbers were scaled by a factor of 0.97 to account for anharmonicity and other deficiencies in the calculations. This level of calculation has been shown to be very reliable for the $S_{0}$ vibrational wavenumbers of a range of substituted benzenes. In the following, we shall calculate vibrational wavenumbers for the actual molecule, but also vibrational wavenumbers that are calculated using the force field of one molecule, but then artificially changing the mass of one or two atoms to match those of particular substituents (atomic or otherwise). In this way, 
we are able to map out changes in the vibrational wavenumbers that occur solely from the mass effect and so identify any deviations from these. In addition, we shall calculate generalized Duschinsky matrices using FC-LabII [20] to illustrate the expression of the vibrations of one molecule in terms of another. For each molecule, we show results for a specific conformer, which will be the lowest energy one that we found at the indicated level of theory.

\section{Labelling the $S_{0}$ vibrational modes of $m \mathrm{DFB}$}

We have previously described our methodology in great detail in Refs. [5 and 6]. We will thus present our results, only including previous detail when necessary for clarity.

We begin first by comparing the vibrations of $m \mathrm{DFB}$ with those of benzene. Similar to the situation in Ref. [7], a choice must be made about the axis system to be used. For ease of comparison we require the atoms in the molecule to be aligned in a way that each atom of the first molecule must appear superimposed on an atom of the second molecule. We therefore choose to place both $m \mathrm{DFB}$ and benzene in the $y z$ plane with the $z$ axis passing through a $\mathrm{C}-\mathrm{H}$ bond, and we select the one that is located between the C-F bonds for $m \mathrm{DFB}-$ see Fig. 1.

Figure 1 represents a way of visualizing the vibrations of $m$ DFB expressed in terms of those of benzene via a Duschinsky matrix approach. This method allows one set of vibrations to be fully expressed as linear combinations of another set of vibrations. The shading, noted in the figure caption, indicates the degree of similarity between the vibrations in the two molecules, with black meaning the vibrations are identical, and shades of grey quantitatively representing the degree of similarity. The data we extract from the Duschinsky matrix is also presented in a different form in Table 1.We have previously noted that there are some caveats regarding setting up the Duschinsky matrix, in terms of which axis system is chosen, and the reader is directed to Ref. [7] for these; here we shall move onto the results of our comparisons. The key conclusion from both Figure 1 and Table 1 is that in many cases the modes of one molecule can only be expressed as significant mixtures of those of the other. Hence, in the majority of cases, it is not possible to associate a single Wilson label with a particular mode of $m \mathrm{DFB}$ leading us to, once again, conclude that the Wilson labels are not suitable labels.

We then move on to compare the modes of $m \mathrm{DFB}$ with those of monofluorobenzene (FBz) (with the latter using the $M_{i}$ labels of Ref. [5]) using the same approach. Figure 2 once again shows a Duschinsky matrix, allowing us to ascertain the degree of mixing between the vibrational modes. We have placed both molecules in the $y z$ plane with the $z$ axis passing 
through the $\mathrm{C}-\mathrm{F}$ bond in $\mathrm{FBz}$ and passing through the same $\mathrm{C}-\mathrm{H}$ bond in $m \mathrm{DFB}$ as before, this is shown in Fig. 2. This separates the vibrations of both molecules into the $a_{1}, a_{2}, b_{1}$ and $b_{2} C_{2 v}$ symmetry classes, and no mixing occurs between different classes. We present a breakdown of the $m$ DFB vibrations in terms of those of the monosubstituted vibrations, employing the $M_{i}$ labels, in Table 1. As can be seen from both Fig. 2 and Table 1, many of the $m$ DFB vibrations are formed from significant mixtures of the FBz vibrations, with only a small number of vibrations remaining largely unchanged and therefore, unsurprisingly given the conclusions for this approach for both the para- and ortho-disubstituted benzene molecules, it is apparent that one cannot use the monosubstituted benzene vibrational labels to describe the vibrations in $m \mathrm{DFB}$.

We now consider how the vibrations of benzene evolve into those of $m \mathrm{DFB}$ as we artificially change the mass of two hydrogen atoms in the meta-positions stepwise, from 1 amu through $19 \mathrm{amu}$. This mass correlation approach maintains a constant force field and hence neglects any electronic effects on the vibrational wavenumbers. We may, therefore, obtain a mass-only view of any changes to the benzene vibrations. We once again align the molecules (as we did above) so that the vibrations are separated into the $C_{2 v}$ symmetry classes. Figure 3 shows the plot for the in-plane $a_{1}$ and $b_{2}$ symmetry vibrations with the full range of wavenumbers shown, while Figure 4 shows all four of the $C_{2 v}$ symmetry classes, but with the omission of the highwavenumber vibrations for the $a_{1}$ and $b_{2}$ classes. We first consider the evolution of the benzene vibrations to those of $m \mathrm{DFB}$, which can be seen when moving from the centre of the diagram towards the left-hand side of each plot in Figs. 3 and 4. The same trends can be seen here as were previously seen in Refs. [6] and [7] in that there are stark changes in wavenumber as the mass changes, particularly within the first $10 \mathrm{amu}$. There are also a number of curves which appear to undergo "avoided crossings". We note that when this occurs the vibrations involved are seen to become mixtures of one another, but that this mixing settles down when the curves separate again after the crossing. After about $10 \mathrm{amu}$, most of the curves start to level off, and we describe this as the point at which the normal modes stabilize and remain largely unchanged with any further mass change. In terms of the evolution of the vibrations of benzene to those of para-disubstituted benzenes, similar trends were seen [6], and the reader is directed to this work for a more in-depth analysis; similar comments apply to ortho-disubstituted benzenes [7]. This confirms that the meta-disubstituted benzenes are also not adequately represented by the Wilson labels. 
We have previously discussed in Ref. [7] why we cannot use the ${ }^{p} D_{i}$ labels for orthodisubstituted benzenes and vice versa. The right hand side of Figures 3 and 4 each display the evolution of benzene to $p$ DFB via the same stepwise change of mass of the indicated hydrogen atoms shown in the diagram. To allow for straightforward comparison, we have aligned the axis system in such a way that both molecules maintain the same $C_{2 v}$ symmetry elements as the mass is varied, allowing the direct correlation of the $p$ DFB vibrations on the right-hand side with those of the $m$ DFB vibrations on the left. This axis system is the same as the one employed in Ref. [6], but not the same as the one employed in Ref. [7]. The choice of this particular $C_{2}$ axis for $p$ DFB leads to $3 a_{2}+6 b_{1}$ out-of-plane modes and $11 a_{1}+10 b_{2}$ in-plane modes and these match those of $m \mathrm{DFB}$, allowing for a mode-by-mode comparison. $p \mathrm{DFB}$ itself belongs to the $D_{2 h}$ point group, and so each vibration has $u$ or $g$ symmetry - we have used colour within both Fig. 3 and Fig. 4 to allow the reader to identify which lines correspond to which symmetry class. Importantly, lines of the same colour, and thus the same symmetry, are not allowed to cross and will undergo avoided crossings (such as with ${ }^{p} D_{28}$ and ${ }^{p} D_{29}$ in Fig. 4); on the other hand, lines of different colours (e.g. ${ }^{p} D_{18}$ and $\left.{ }^{p} D_{19}\right)$ can cross. In each of the left-hand quadrants of each diagram in Fig. 4 no lines can cross as they are all of the same $C_{2 v}$ symmetry class.

The mass-correlation curves, as well as the mixings indicated in Table 1, may be used complementarily in order to gain insight into the mixings occurring between different vibrations. Perhaps the most important point is that, if one traces the curves in Figs. 3 and 4 from one side $(p \mathrm{DFB})$ to the other side $(m \mathrm{DFB})$, there are a number of avoided crossings occurring and, therefore, significant mixing of the modes. In Fig. 5 we show a Duschinsky matrix comparing the vibrational modes of $p$ DFB to those of $m \mathrm{DFB}$ and it is noticeable that a number of the vibrations are heavily mixed and, therefore, there is not a 1:1 correspondence between the $p \mathrm{DFB}$ and $m \mathrm{DFB}$ vibrations. Thus we make an analogous conclusion to that in Ref. [7], that the vibrations of $m \mathrm{DFB}$ and $p \mathrm{DFB}$ also cannot be consistently labelled using a single scheme.

We also show that we cannot use the ${ }^{o} D_{i}$ labels of Ref. [7] as a way of labelling the modes of $m$ DFB. Again, the Duschinsky matrix approach requires that the each atom for $o \mathrm{DFB}$ be aligned with another atom of $m \mathrm{DFB}$. With $m \mathrm{DFB}$ and $o \mathrm{DFB}$, however, it is not possible to align so that the same $C_{2 v}$ axis system is maintained for both molecules, since this would require the $z$ axis both to intersect the $\mathrm{C}-\mathrm{C}$ bond bridging the $\mathrm{C}-\mathrm{F}$ bonds in $o \mathrm{DFB}$ and pass through the $\mathrm{C}-\mathrm{H}$ bond between the two $\mathrm{C}-\mathrm{F}$ bonds in $m \mathrm{DFB}$. The same $C_{2 v}$ symmetry elements can therefore not be achieved for both molecules and, as a result, mixing of $a_{1}$ with $b_{2}$ and $a_{2}$ with 
$b_{1}$ modes is seen - see Ref. [7] for a discussion of these points when comparing the vibrations of ortho-disubstituted benzenes with those of the corresponding para species. We show comparisons for two axis systems in Figure 6 where, in each case, we have aligned one of the $\mathrm{C}-\mathrm{F}$ bonds in each molecule. It may clearly be seen that there is not a 1:1 correspondence between the vibrations of the ortho and meta species.

In summary, we have previously shown that we require a separate labelling scheme for each of the mono-substituted, para-, and ortho-disubstituted benzenes; here, we have demonstrated the same for meta-disubstituted benzenes.

We now move on to describing the use of the vibrational modes of $m \mathrm{DFB}$ as a basis for labelling the meta-disubstituted benzenes. Similar to Refs [2], [6] and [7], we present mass correlation diagrams in Fig. 7. These employ the force field of $m$ DFB while changing the masses of both $\mathrm{F}$ atoms simultaneously to match that of each of the halogens, where we choose the most abundant isotope in each case. The curves all appear to remain mostly flat, with some lines tending towards slightly lower wavenumber with mass. There are no signs of avoided crossings in the curves and, hence, no obvious signs of significant mixing and hence no significant changes in vibrational character. Similarly, in Fig. 8, we employ the force field of $m \mathrm{DFB}$ and vary the mass of a single $\mathrm{F}$ atom to match the other halogens. The same trend is noted in that, although there is a decrease in the wavenumber of some vibrations, the vibrational character does not significantly change. This is still ostensibly the case, even though the molecular point group symmetry has now lowered to $C_{s}$ for these asymmetric substitutions, and there are now avoided crossings, such as between the vibrations labelled 19 and 20. This is also confirmed in both cases by the relevant Duschinsky matrices which show largely diagonal character which we do not show here. As a result of this, we use the normal modes of $m \mathrm{DFB}$ as a basis for labelling the vibrational modes of meta-disubstituted benzenes. As in the ortho-disubstituted benzenes [7], we desire the labels to be widely applicable to symmetric and asymmetric meta-disubstituted benzenes, and so we construct these labels in the $C_{s}$ point group denoting them as ${ }^{m} D_{i}$ in a similar way that we have done for the other two isomers, where the pre-superscript denotes 'meta' and the post-subscript denotes the number of the vibration; the pre-superscript is generally only required when distinction between isomers is needed. We restrict our labels to the phenyl-ring localized modes, and so any substituents are treated as point masses and their localized modes are treated separately. 
In summary, we propose the use of the ${ }^{m} D_{i}$ labels for the phenyl-ring-localized vibrations of meta-disubstituted benzenes. We have included a diagrammatic representation of each vibrational mode in Fig. 9. It is straightforward to assign a label to a vibration by simply visualizing the motion via quantum chemical calculations, or through analysis of the mass correlation trends or via a Duschinsky matrix comparison. There are, however, two pairs of modes which require an element of caution. As we have seen previously in both ortho- and para-disubstituted benzene molecules, there are cases whereby modes that are symmetric and asymmetric stretches in symmetrically-substituted molecules, evolve into localized stretching modes. In Fig. 10, the $D_{10}$ and $D_{13}$, and $D_{18}$ and $D_{19}$, pairs of vibrations are shown, and can be seen to demonstrate localized character; this will occur when the difference in mass for the substituents is large. What is noticeable is that $D_{10}$, which is a symmetric in-phase substituent stretch, and $D_{13}$, which is an asymmetric, out-of-phase stretch, become localized C-X and C-Y stretches (where $\mathrm{X}$ and $\mathrm{Y}$ denote different substituents). Similarly, $D_{18}$ has symmetric in-phase stretch character whereas $D_{19}$ has out-of-phase asymmetric stretch character, and these modes become localized C-X and C-Y stretches. This will be discussed further in the below, in relation to particular substituents.

\section{Assigning the vibrations}

We now consider families of different meta-disubstituted benzenes and for each we present a summary of both calculated and experimental vibrational wavenumbers, as well as discussing previous assignments and any changes that we have made. We consider symmetrically disubstituted benzenes involving halogen atoms, $\mathrm{OH}$ and $\mathrm{CH}_{3}$ groups; and asymmetric dihalobenzenes, halotoluenes, halophenols and cresol.

\subsection{Symmetric disubstituted benzenes}

A summary of both experimental and calculated vibrational wavenumbers can be found in Table 2. $m \mathrm{DFB}$, in its ground electronic state $\left(\tilde{X}^{1} A_{1}\right)$, has $C_{2 v}$ symmetry and 30 normal vibrational modes. Most experimental data for the dihalogens have been taken from a summary by Green [21], where the presented data have been extracted from previous liquid or solution phase infrared studies [22,23,24]; available Raman studies from Refs. [25,26,27] are also summarized in Ref. 20. In Table 2, for consistency, we favour the infrared values over the Raman values where both are available. We also present updated experimental values for $m \mathrm{DFB}$, which we extract from the jet-cooled dispersed fluorescence study by Graham and Kable [28]; we use values taken from gas-phase studies where possible, as these are directly 
comparable to our calculated values since they are not affected by perturbations due to solvent effects. Notably, in a few cases, we have re-ordered the vibrations to give like-motions the same ${ }^{m} D_{i}$ label; the wavenumber ordering for some vibrations may therefore change from that of $m \mathrm{DFB}$ - the experimental values have also been switched to take into account these changes. To maintain our objective of the ${ }^{m} D_{i}$ labels being applicable to all meta-disubstituted benzenes, we have separated the vibrations into $a^{\prime}$ and $a^{\prime \prime}$ symmetry; but also, for clarity, in Table 2 we also give the $C_{2 v}$ Mulliken label that was used in Ref. 28. Experimental vibrational wavenumbers for $m \mathrm{DClB}, m \mathrm{DBrB}, m \mathrm{DIB}$ and meta-xylene ( $m \mathrm{Xyl})$ are all also extracted from the review by Green (Ref. 20). (Note that the abbreviations for the molecules follow the same logic as used above, with the halogen chemical symbol employed as appropriate.)

There have been several studies on resorcinol by Wilson [29], Kudchadker et al. [30] as well as Hidalgo and Otero [31]; we have preferred the gas phase values recorded by Wilson where available. There are, however, a number of uncertain and/or incomplete assignments and so we have also used a number of values from Ref. [30] when necessary. We have made our assignments of the vibrations taking account of the given symmetry from the papers, the comments noted by the authors, as well as through comparison with calculated data. The conformers employed in the calculations for resorcinol and $m \mathrm{Xyl}$ are given in the footnote of Table 2.

We present our calculated wavenumbers in Table 2 and, for the most part, there is very good agreement between theory and experiment, with only a small number of missing experimental values. In the majority of cases, the vibrational modes are fairly straightforward to identify across the family of substituted benzenes. Many of the experimental assignments deduced the symmetry of each vibrational mode via the band profile and/or comparing infrared and Raman activity. We note that the ordering of vibrations changes for the heavier dihalogens between $D_{10}$ and $D_{14}$, as well as between $D_{18}$ and $D_{20}$ - this is apparent because of the same label being used for the same vibration, and arises from some energetically-close vibrations undergoing small changes in vibrational wavenumber with increasing substituent mass. We also note that the calculated and experimental [20] values for the $D_{19}$ vibration of $m \mathrm{DIB}$ are not in good agreement, $308 \mathrm{~cm}^{-1}$ and $164 \mathrm{~cm}^{-1}$, respectively, and we conclude that the experimental value is incorrect. It was noted in Ref. 20 that there were two weak bands observed at $1265 \mathrm{~cm}^{-1}$ and $1243 \mathrm{~cm}^{-1}$ either of which could be assigned to $D_{11}$, we have preferred $1243 \mathrm{~cm}^{-1}$ as it more closely matches our calculated value. Assignments for the dihalogens are otherwise consistent with the calculated data for the explicit molecules presented in Table 2, and we therefore make 
no further changes. Fig. 7 also shows a mass correlation plot where we compare experimental values to the calculated ones obtained with the $m \mathrm{DFB}$ force-field and using artificial isotopes - in many cases the plots shows a high degree of concurrence between the experimental and calculated wavenumbers and suggests electronic effects are generally small. In cases where there is some deviation, this is thought to be indicative of electronic changes, such as variation in the force constant of one or more bonds; these still result in largely similar motions (but see the asymmetric cases below).

For $m \mathrm{Xyl}$, infrared studies from the liquid phase and their corresponding assignments from various studies [32,33,34] have been summarized in Green [20]. Selco and Carrick [35] have also performed a jet-cooled emission study. We favour values from the emission study over the infrared, when available, for the same reasons mentioned above. The correspondence between calculated and experimental data are, once again, mostly good. In Refs. [20] and [35] a C-C bending mode is assigned a value of $1467 \mathrm{~cm}^{-1}$ and $1460 \mathrm{~cm}^{-1}$, respectively; however, we do not calculate a value close to these with our closest calculated value being $1408 \mathrm{~cm}^{-1}$ $\left(D_{8}\right)$. This poor agreement suggests that neither of these experimental values matches a calculated vibrational fundamental, and we therefore choose not to associate those experimental values with $D_{8}$.

\subsection{Asymmetric dihalobenzenes}

Table 3 presents a summary of the available experimental vibrational wavenumbers as well as our calculated values. The experimental data for the asymmetric meta-dihalobenzenes has been taken from Ref. [20] which is, once again, mostly data collected from liquid phase infrared spectroscopy studies. Any gaps in the IR study have been filled with Raman studies from Ref. [36]. As noted above, to allow for comparison between all families of meta-disubstituted benzenes, we have employed the same ${ }^{m} D_{\mathrm{i}}$ labels despite the symmetry of these molecules being different to those of the symmetric meta-disubstituted benzenes. Where necessary, once again we have changed the ordering of the corresponding experimental vibrational wavenumbers. There only appear to be a small number of missing experimental values and we see that, in general, the agreement with the calculated values is mostly very good. As in the symmetric meta-disubstituted benzenes, we see that the wavenumber ordering of the vibrations changes between $D_{9}$ and $D_{14}$ as well as $D_{18}$ and $D_{20}$ compared to $m \mathrm{DFB}$. We note, however, that the vibrational modes themselves are mostly unchanged and can be fairly obviously assigned, apart from the cases where local modes form upon substitution, discussed below. 
Interestingly, we find the agreement between the experimental and calculated values of 202 $\mathrm{cm}^{-1}$ and $155 \mathrm{~cm}^{-1}$ for $D_{21}$ of $m$ ClIB as well as between the corresponding values, $147 \mathrm{~cm}^{-1}$ and $106 \mathrm{~cm}^{-1}$, for $m \mathrm{BrIB}$ is fairly poor, and hence conclude those assignments were incorrect. As we have previously noted in Refs. [6] and [7], we did not always see the symmetric and asymmetric $\mathrm{C}$-X stretching modes of a symmetrically-substituted benzene evolve into localized $\mathrm{C}-\mathrm{X}$ and $\mathrm{C}-\mathrm{Y}$ stretches in the asymmetric cases, as the mass of one of the substituents increased. The localization, where seen, has been indicated in Table 3. As in previous cases, $[6,7]$ we have consistently applied the $D_{10}$ label to the higher-wavenumber C-X stretch, and $D_{13}$ to the lower-wavenumber C-Y stretch. We also note that $D_{18}$ and $D_{19}$ also exhibit a similar degree of localization, and we have labelled these similarly in Table 3. (The main difference between the $D_{10}$ and $D_{18}$ vibrations is the in- and out-of-phase stretch motions of the two C-H groups that are positioned vertically in Figure 10; with similar correspondences between $D_{13}$ and $D_{19}$, albeit reversed.) The localization is not always complete, but the extent is related to the difference in masses, with the highest degree of localization being seen when $\mathrm{X}=\mathrm{F}$ and $\mathrm{Y}=\mathrm{I}$. We note that when the localization is not clear, such as when $\mathrm{X}=\mathrm{Cl}$ or $\mathrm{Br}$, we have labelled the vibrations as asymmetric or symmetric stretches instead. We note from the mass correlation diagrams in Figure 8 that some deviation is seen between the lines calculated with a fixed force field and the experimental data points; this indicates that some force constants are indeed changing, although the motion remains very similar.

\section{3 meta-halotoluenes}

A summary of all available experimental values for the four meta-halotoluenes considered, and our present calculated vibrational wavenumbers, is shown in Table 4, where the lowest calculated energy conformer is indicated in the footnote of the table. The experimental values, once again, are a combination of liquid phase IR and Raman studies both summarized by Green in Ref. [20], where Green extracted the Raman data from Ref. [24]. As before, we have given vibrations with similar motions the same ${ }^{m} D_{i}$ label, which leads to the ordering of the vibrations changing in some places compared to those of $m \mathrm{DFB}$ - the experimental vibrational wavenumbers have also been changed to match. There are only a few missing vibrational wavenumbers, notably in the range of $>3000 \mathrm{~cm}^{-1}$. The agreement is generally good between calculated and experimental data; there are some notable discrepancies particularly for $D_{5}, D_{8}$, $D_{10}$ and $D_{19}$ where the differences seem fairly large. This may be due, in part, to some coupling between methyl-localized modes and ring-localized modes that we have previously noted in Refs. [2], [6] and [7]. (We remind the reader that the ${ }^{m} D_{i}$ labels only cover ring-localized 
vibrations and the methyl-group vibrations are treated as separate.) The differences between calculated and experimental values for the modes noted above stay relatively constant across the range of the meta-halotoluenes and it still remains relatively easy to track each vibrational mode across the given series of molecules.

Once again, we notice a degree of localization, which was prevalent in the asymmetric dihalobenzenes. In $m \mathrm{DFB}$, the two pairs of vibrations, $D_{10}$ and $D_{13}$, as well as $D_{18}$ and $D_{19}$, constitute a symmetric and asymmetric C-F stretch. In the halotoluenes, localization occurs in most cases, to yield a $\mathrm{C}-\mathrm{Me}$ stretch and a $\mathrm{C}-\mathrm{X}$ stretch $\left(\mathrm{X}=\right.$ halogen, $\left.\mathrm{Me}=\mathrm{CH}_{3}\right)$. We note that this is not the case in $m \mathrm{FT}$, but does occur from $m \mathrm{ClT}$ onwards. We have reflected this observation in Table 4 where we always assign $D_{10}$ and $D_{18}$ (when appropriate) to the carbonmethyl (C-Me) stretch and the $D_{13}$ and $D_{19}$ to the carbon-halogen stretches (C-X).

\section{4 meta-halophenols and meta-cresol}

A summary of the available experimental and present calculated vibrational wavenumbers for the phenyl-localized vibrations of the meta-halophenols and meta-cresol are presented in Table 5. The conformer employed has once again been noted in the footnote of the table. The experimental values have been taken from Green [37], where a combination of solution and liquid phase IR values are given. Raman values have also been incorporated from Refs. [24] and [35]. We have given vibrations with similar motions the same ${ }^{m} D_{i}$ label, which may lead to the ordering of the vibrations changing relative to that for $m \mathrm{DFB}$ - the experimental values have been reordered to reflect these changes. Once again the agreement between the calculated and experimental data are very good and the trends in the vibrations may be followed across the series of molecules. We again note that the hydroxyl group vibrations, as well as the methyl group vibrations of meta-cresol, do not form part of the ${ }^{m} D_{i}$ labelling scheme and should be treated separately.

We see localization of the C-OH and C-X stretches in the $D_{10}$ and $D_{13}$ vibrations, as well as in the $D_{18}$ and $D_{19}$ modes. We use the $D_{10}$ and $D_{18}$ labels for the C-OH stretches, with $D_{13}$ and $D_{19}$ being used for the $\mathrm{C}-\mathrm{X}$ stretches. The exception is for $m \mathrm{FPhOH}$ where we retain the symmetric/asymmetric labels as the degree of localization is not complete. This is very similar to the case of the meta-halotoluenes discussed above. 


\section{Conclusions}

In the present work, we have shown that it is possible to label the phenyl-localized vibrations of a range of meta-disubstituted benzenes consistently, where vibrations with the same or very similar atomic motion are associated with the same label. Throughout the study, we see that the ordering of the vibrations changes between species as a result of differing mass effects relating to the substituents. This would mean that the application of the usual Mulliken (Herzberg) labelling scheme, even for the same family of molecules, would give different labels to vibrational modes with the same atomic motions. We have shown how the motions of meta-disubstituted benzenes are related to other species (benzene, monosubstituted benzenes, para-disubstituted benzenes and ortho-disubstituted benzenes), and shown that the vibrations are often heavily mixed versions of one another. This leads us to conclude that the vibrational motions of the meta-disubstituted benzenes are significantly different to those of the other isomers, and this means that different labelling schemes are required for each. It is worth noting that some caution is required when applying the labels as the centres of mass shift somewhat for differing isomers or in the case of asymmetric substitution. Although the $z$-axis remains fixed to the centre of mass, the changes in its position lead to distortions of the motions of some of the atoms to compensate. This issue proves not to be overly problematic, and it was still possible to trace the modes as a function of mass with a fixed force-field and to identify which vibrational mode corresponded to which ${ }^{m} D_{i}$ label. As noted for the para- and ortho-disubstituted benzenes, significant localization occurs in pairs of modes involving symmetric and asymmetric substituent stretches.

We anticipate that this labelling scheme for meta-disubstituted benzenes will be useful in unearthing trends in vibrational activity between molecules, as we have noticed when examining the vibrationally resolved electronic and photoelectron spectra of both monosubstituted and para-disubstituted benzenes (see references cited above). 


\section{Acknowledgements}

We are grateful to the EPSRC for funding via grant EP/L021366/1. The EPSRC and the University of Nottingham are thanked for studentships to A.A., D.J.K and W.D.T. We are grateful to the High Performance Computer resource at the University of Nottingham for the provision of computer time. 
Table 1. Labelling schemes for the $S_{0}$ vibrations of $m \mathrm{DFB}$

\begin{tabular}{|c|c|c|c|c|}
\hline Mode $^{a}$ & $\begin{array}{l}\text { Mulliken } \\
C_{2 v}{ }^{\mathrm{b}}\end{array}$ & $m \mathrm{DFB}$ - Varsányi ${ }^{\mathrm{c}}$ & Mixed $(B z)^{c, d}$ & Mixed $(\mathrm{FBz})^{\mathrm{e}}$ \\
\hline \multicolumn{5}{|c|}{$a^{\prime}$} \\
\hline${ }^{m} D_{1}\left(a_{1}\right)$ & 1 & $20 \mathrm{~b}$ & $20 a, 7 a,(2,13)$ & $M_{6}, M_{11},\left(M_{10}\right)$ \\
\hline${ }^{m} D_{2}\left(a_{1}\right)$ & 2 & 2 & $2,20 \mathrm{a},(13)$ & $M_{2}, M_{30},\left(M_{3}\right)$ \\
\hline${ }^{m} D_{3}\left(b_{2}\right)$ & 21 & $7 a$ & 20b, $7 \mathrm{~b}$ & $M_{21},\left(M_{14}\right)$ \\
\hline${ }^{m} D_{4}\left(a_{1}\right)$ & 3 & $20 \mathrm{a}$ & $7 a, 13,(20 a)$ & $M_{3}, M_{2}$ \\
\hline${ }^{m} D_{5}\left(a_{1}\right)$ & 4 & $9 \mathrm{a}$ & 9a & $M_{4}$ \\
\hline${ }^{m} D_{6}\left(b_{2}\right)$ & 22 & $9 \mathrm{~b}$ & $9 \mathrm{~b}$ & $M_{22}$ \\
\hline${ }^{m} D_{7}\left(b_{2}\right)$ & 23 & $18 \mathrm{~b}$ & $18 b$ & $M_{23}$ \\
\hline${ }^{m} D_{8}\left(a_{1}\right)$ & 5 & $18 \mathrm{a}$ & 18a, (8a, 19a) & $\boldsymbol{M}_{5},\left(M_{8}\right)$ \\
\hline${ }^{m} D_{9}\left(b_{2}\right)$ & 24 & 14 & 15, (3) & $M_{25},\left(M_{24}\right)$ \\
\hline${ }^{m} D_{10}\left(a_{1}\right)$ & 6 & 13 & $1,(12,13,2,18 a, 7 a, 20 a)$ & $M_{9},\left(M_{30}, M_{2}, M_{5}\right)$ \\
\hline${ }^{m} D_{11}\left(b_{2}\right)$ & 25 & 3 & $\mathbf{3},(8 \mathrm{~b}, 19 \mathrm{~b}, 15,14)$ & $M_{24}, M_{27},\left(M_{29}\right)$ \\
\hline${ }^{m} D_{12}\left(b_{2}\right)$ & 26 & $8 \mathrm{~b}$ & $14,8 \mathrm{~b},(19 \mathrm{~b})$ & $M_{26},\left(M_{29}, M_{14}\right)$ \\
\hline${ }^{m} D_{13}\left(b_{2}\right)$ & 27 & $19 \mathrm{~b}$ & $8 b,(19 b, 7 b, 20 b, 6 b, 18 b)$ & $M_{29},\left(M_{14}, M_{26}\right)$ \\
\hline${ }^{m} D_{14}\left(a_{1}\right)$ & 7 & $19 \mathrm{a}$ & 19a, 8a & $M_{8}, M_{7},\left(M_{6}, M_{9}\right)$ \\
\hline${ }^{m} D_{15}\left(a_{1}\right)$ & 8 & 12 & $\mathbf{1 2}, 1$ & $M_{6}, M_{10},\left(M_{8}\right)$ \\
\hline${ }^{m} D_{16}\left(b_{2}\right)$ & 28 & $7 \mathrm{~b}$ & $19 b,(6 b, 7 b, 20 b, 14,8 b)$ & $M_{28},\left(M_{14}, M_{27}, M_{24}, M_{25}, M_{23}\right)$ \\
\hline${ }^{m} D_{17}\left(a_{1}\right)$ & 9 & 1 & $6 a,(1,12,13,2)$ & $M_{9}, M_{11},\left(M_{30}, M_{10}, M_{2}\right)$ \\
\hline${ }^{m} D_{18}\left(a_{1}\right)$ & 10 & $6 a$ & 6a, $(13,2,1)$ & $M_{10}, M_{11},\left(M_{30}, M_{9}, M_{2}\right)$ \\
\hline${ }^{m} D_{19}\left(b_{2}\right)$ & 29 & $6 \mathrm{~b}$ & $\mathbf{6 b},(20 \mathrm{~b}, 7 \mathrm{~b})$ & $M_{28},\left(M_{14}, M_{27}, M_{29}\right)$ \\
\hline${ }^{m} D_{20}\left(b_{2}\right)$ & 30 & 15 & $(14,3,8 b, 19 b, 6 b)$ & $M_{27},\left(M_{24}, M_{28}, M_{25}\right)$ \\
\hline${ }^{m} D_{21}\left(a_{1}\right)$ & 11 & $8 \mathrm{a}$ & $8 a, 19 a(18 a)$ & $M_{7}, M_{8},\left(M_{5}\right)$ \\
\hline \multicolumn{5}{|c|}{$a^{\prime \prime}$} \\
\hline${ }^{m} D_{22}\left(b_{1}\right)$ & 15 & 4 & $\mathbf{1 7 b}, 5$ & $M_{1},\left(M_{15}\right)$ \\
\hline${ }^{m} D_{23}\left(a_{2}\right)$ & 12 & $17 \mathrm{a}$ & 17a, 10a & $\boldsymbol{M}_{\mathbf{2 0}},\left(M_{12}\right)$ \\
\hline${ }^{m} D_{24}\left(b_{1}\right)$ & 16 & $17 \mathrm{~b}$ & $17 \mathrm{~b}, 5,(11,10 \mathrm{~b}, 4)$ & $\left(M_{15}, M_{18}, M_{17}, M_{19}, M_{16}\right)$ \\
\hline${ }^{m} D_{25}\left(b_{1}\right)$ & 17 & 11 & 10b, (11) & $M_{16},\left(M_{15}, M_{17}, M_{19}, M_{1}\right)$ \\
\hline${ }^{m} D_{26}\left(b_{1}\right)$ & 18 & 5 & $4,(11)$ & $M_{17}, M_{16},\left(M_{18}, M_{19}\right)$ \\
\hline${ }^{m} D_{27}\left(a_{2}\right)$ & 13 & $16 \mathrm{a}$ & $16 a, 10 a,(17 a)$ & $M_{13}, M_{12}$ \\
\hline${ }^{m} D_{28}\left(b_{1}\right)$ & 19 & $16 \mathrm{~b}$ & $\mathbf{1 6 b},(11)$ & $M_{19}, M_{18},\left(M_{17}, M_{16}, M_{15}\right)$ \\
\hline${ }^{m} D_{29}\left(a_{2}\right)$ & 14 & $10 \mathrm{a}$ & 16a, (10a, 17a) & $M_{13},\left(M_{12}, M_{20}\right)$ \\
\hline${ }^{m} D_{30}\left(b_{1}\right)$ & 20 & $10 \mathrm{~b}$ & $17 \mathbf{b}, 5$ & $M_{18},\left(M_{17}, M_{15}\right)$ \\
\hline
\end{tabular}

${ }^{\text {a }}$ This work - see text. Labels are based on Mulliken numbering via the $\mathrm{C}_{s}$ symmetry group, with the $C_{2 v}$ symmetry class given in parentheses.

${ }^{\mathrm{b}}$ Mulliken numbering via the $C_{2 v}$ symmetry group

${ }^{c}$ We have previously highlighted (Ref. 5) that several Wilson modes have been misnumbered throughout various texts in the last number of years. The following switches are often required: $8 \mathrm{a} \leftrightarrow 9 \mathrm{a}, 8 \mathrm{~b} \leftrightarrow 9 \mathrm{~b}, 18 \mathrm{a} \leftrightarrow 19 \mathrm{a}, 18 \mathrm{~b} \leftrightarrow 19 \mathrm{~b}$, $3 \leftrightarrow 14$. These switches have been made where these have occurred throughout the present work.

${ }^{\mathrm{d}}$ These express the $\mathrm{S}_{0} m \mathrm{DFB}{ }^{m} D_{\mathrm{i}}$ vibrational modes in terms of those of the benzene Wilson modes using a generalized Duschinsky approach involving artificial isotopologues - see text and Ref. 5 for more details. Values outside parentheses have mixing coefficients $>0.2$ and are termed major contributions, with bolded values being dominant contributions (mixing coefficients $>0.5$ ). Those inside parentheses have mixing coefficients between 0.05 and 0.2 and are termed minor contributions. If there are multiple contributions of each type, these are given in the order of largest contribution first. Vibrations with a mixing coefficient $<0.05$ are ignored.

${ }^{\mathrm{e}}$ These express the $\mathrm{S}_{0} m \mathrm{DFB}{ }^{m} D_{\mathrm{i}}$ vibrational modes in terms of those of fluorobenzene, numbered as $M_{i}$ modes, using a generalized Duschinsky approach involving artificial isotopologues - see text and Ref. 5 for more details. Values outside parentheses have mixing coefficients $>0.2$ and are termed major contributions, with bolded values being dominant contributions (mixing coefficients $>0.5$ ). Those inside parentheses have mixing coefficients between 0.05 and 0.2 and are termed minor contributions. If there are multiple contributions of each type, these are given in the order of largest contribution first. Vibrations with a mixing coefficient $<0.05$ are ignored. 
Table 2. Vibrational wavenumber for $m-\mathrm{C}_{6} \mathrm{H}_{4} \mathrm{X}_{2}\left(\mathrm{X}=\mathrm{F}, \mathrm{Cl}, \mathrm{Br}, \mathrm{I}, \mathrm{CH}_{3}\right.$ and $\left.\mathrm{OH}\right)$

\begin{tabular}{|c|c|c|c|c|c|c|c|c|c|c|c|c|c|}
\hline \multicolumn{2}{|c|}{ Mode } & \multicolumn{2}{|c|}{$m \mathrm{Xyl}$} & \multicolumn{2}{|c|}{ Resorcinol } & \multicolumn{2}{|c|}{$m \mathrm{DFB}$} & \multicolumn{2}{|c|}{$m \mathrm{DClB}$} & \multicolumn{2}{|c|}{$m \mathrm{DBrB}$} & \multicolumn{2}{|c|}{$m \mathrm{DIB}$} \\
\hline$D_{i}$ & $C_{2 v}$ & $\operatorname{Expt}^{\mathrm{a}}$ & $\mathrm{Calc}^{\mathrm{b}}$ & $\mathrm{Expt}^{\mathrm{c}}$ & $\mathrm{Calc}^{\mathrm{b}}$ & $\operatorname{Expt}^{\mathrm{a}}$ & $\mathrm{Calc}^{\mathrm{b}}$ & $\operatorname{Expt}^{a}$ & $\mathrm{Calc}^{\mathrm{b}}$ & $\operatorname{Expt}^{\mathrm{a}}$ & $\mathrm{Calc}^{\mathrm{b}}$ & $\operatorname{Expt}^{\mathrm{a}}$ & $\mathrm{Calc}^{\mathrm{b}}$ \\
\hline \multicolumn{14}{|c|}{$a^{\prime}$} \\
\hline${ }^{m} D_{1}\left(a_{1}\right)$ & 1 & 3052 & 3085 & 3064 & 3109 & $3095^{\mathrm{f}}$ & 3122 & 3071 & 3124 & 3078 & 3123 & 3070 & 3119 \\
\hline${ }^{m} D_{2}\left(a_{1}\right)$ & 2 & 3050 & 3050 & 3053 & 3078 & 3086 & 3116 & - & 3115 & 3058 & 3115 & 3070 & 3112 \\
\hline${ }^{m} D_{3}\left(b_{2}\right)$ & 21 & 3032 & 3068 & 3039 & 3086 & 3086 & 3112 & 3095 & 3111 & 3078 & 3111 & 3055 & 3108 \\
\hline${ }^{m} D_{4}\left(a_{1}\right)$ & 3 & - & 3059 & 3036 & 3068 & - & 3090 & - & 3087 & - & 3085 & 3046 & 3081 \\
\hline${ }^{m} D_{5}\left(a_{1}\right)$ & 4 & $1584^{\mathrm{d}}$ & 1579 & 1607 & 1594 & $1611^{\mathrm{e}}$ & 1597 & 1577 & 1563 & 1567 & 1556 & 1553 & 1547 \\
\hline${ }^{m} D_{6}\left(\mathrm{~b}_{2}\right)$ & 22 & 1613 & 1597 & 1614 & 1606 & $1613^{\mathrm{e}}$ & 1592 & 1577 & 1561 & 1567 & 1553 & 1553 & 1542 \\
\hline${ }^{m} D_{7}\left(b_{2}\right)$ & 23 & 1492 & 1482 & 1502 & 1487 & 1490 & 1475 & 1462 & 1450 & 1460 & 1446 & 1449 & 1441 \\
\hline${ }^{m} D_{8}\left(a_{1}\right)$ & 5 & $-{ }^{f}$ & 1408 & 1486 & 1469 & 1435 & 1439 & 1412 & 1399 & 1412 & 1392 & 1402 & 1384 \\
\hline${ }^{m} D_{9}\left(b_{2}\right)$ & 24 & $1307^{\mathrm{d}}$ & 1310 & $1304^{j}$ & 1309 & 1337 & 1304 & 1289 & 1290 & 1292 & 1288 & 1292 & 1290 \\
\hline${ }^{m} D_{10}\left(a_{1}\right)$ & 7 & $1252^{\mathrm{i}}$ & 1233 & 1299 & 1285 & $1292^{\mathrm{c}}$ & 1255 & $1124^{\mathrm{i}}$ & 1096 & $1059^{\mathrm{i}}$ & 1046 & 1047 & $1030^{\mathrm{i}}$ \\
\hline${ }^{m} D_{11}\left(b_{2}\right)$ & 25 & $1266^{\mathrm{d}, \mathrm{i}}$ & 1282 & 1332 & 1332 & 1260 & 1252 & $1258^{\mathrm{i}}$ & 1251 & $1256^{\mathrm{i}}$ & 1253 & 1243 & $1249^{i}$ \\
\hline${ }^{m} D_{12}\left(b_{2}\right)$ & 26 & $1154^{\mathrm{i}}$ & 1145 & 1140 & 1141 & $1157^{\mathrm{e}}$ & 1145 & $1161^{\mathrm{i}}$ & 1152 & $1161^{\mathrm{i}}$ & 1156 & 1176 & $1160^{\mathrm{i}}$ \\
\hline${ }^{m} D_{13}\left(b_{2}\right)$ & 27 & $1167^{\mathrm{i}}$ & 1162 & 1133 & 1135 & 1120 & 1102 & $1080^{\mathrm{h}}$ & 1065 & $1078^{\mathrm{h}}$ & 1064 & 1075 & $1065^{\mathrm{h}}$ \\
\hline${ }^{m} D_{14}\left(a_{1}\right)$ & 6 & $1096^{\mathrm{d}}$ & 1089 & 1075 & 1065 & $1068^{\mathrm{e}}$ & 1058 & 1073 & 1063 & 1096 & 1086 & 1075 & 1085 \\
\hline${ }^{m} D_{15}\left(a_{1}\right)$ & 8 & $1000^{\mathrm{d}}$ & 987 & $1000^{\mathrm{k}}$ & 984 & $1012^{\mathrm{e}}$ & 994 & 997 & 987 & 992 & 983 & 993 & 978 \\
\hline${ }^{m} D_{16}\left(b_{2}\right)$ & 28 & 905 & 893 & - & 947 & $956^{\mathrm{e}}$ & 941 & 784 & 760 & 726 & 710 & 692 & 685 \\
\hline${ }^{m} D_{17}\left(\mathrm{a}_{1}\right)$ & 9 & $724^{d}$ & 716 & 745 & 735 & $739^{\mathrm{e}}$ & 726 & 663 & 655 & 646 & 640 & 639 & 632 \\
\hline${ }^{m} D_{18}\left(a_{1}\right)$ & 10 & 537 & 527 & $565^{\mathrm{k}}$ & 529 & 522 & 514 & $398^{\mathrm{i}}$ & 386 & $287^{\mathrm{ij}}$ & 279 & 201 & 227 \\
\hline${ }^{m} D_{19}\left(\mathrm{~b}_{2}\right)$ & 29 & $514^{\mathrm{d}}$ & 508 & $542^{\mathrm{k}}$ & 514 & $513^{\mathrm{e}}$ & 502 & $429^{g h}$ & 417 & $357^{\mathrm{i}}$ & 346 & $-f^{f}$ & 308 \\
\hline${ }^{m} D_{20}\left(b_{2}\right)$ & 30 & $383^{d}$ & 393 & $494^{\mathrm{k}}$ & 465 & $477^{\mathrm{e}}$ & 467 & 365 & 355 & $308^{j}$ & 302 & 238 & 265 \\
\hline${ }^{m} D_{21}\left(a_{1}\right)$ & 11 & $273^{d}$ & 267 & $356^{\mathrm{k}}$ & 322 & $329^{\mathrm{e}}$ & 320 & 198 & 190 & 159 & 125 & 109 & 92 \\
\hline \multicolumn{14}{|c|}{$a^{\prime \prime}$} \\
\hline${ }^{m} D_{22}\left(b_{1}\right)$ & 15 & 968 & 972 & 956 & 952 & $957^{\mathrm{e}}$ & 963 & 964 & 970 & 968 & 971 & 966 & 971 \\
\hline${ }^{m} D_{23}\left(a_{2}\right)$ & 12 & $905^{\mathrm{j}}$ & 888 & 837 & 841 & $876^{\mathrm{e}}$ & 871 & 892 & 892 & 894 & 894 & 899 & 897 \\
\hline${ }^{m} D_{24}\left(b_{1}\right)$ & 16 & $874^{d}$ & 880 & 816 & 833 & $857^{\mathrm{e}}$ & 856 & 867 & 874 & 868 & 877 & 872 & 881 \\
\hline${ }^{m} D_{25}\left(b_{1}\right)$ & 17 & $769^{d}$ & 768 & 768 & 752 & $771^{\mathrm{e}}$ & 767 & 773 & 773 & 769 & 770 & 768 & 766 \\
\hline${ }^{m} D_{26}\left(b_{1}\right)$ & 18 & 690 & 694 & 680 & 677 & $680^{\mathrm{e}}$ & 671 & 672 & 672 & 669 & 672 & 670 & 666 \\
\hline${ }^{m} D_{27}\left(a_{2}\right)$ & 13 & $538^{\mathrm{j}}$ & 517 & - & 611 & $603^{\mathrm{e}}$ & 597 & 532 & 533 & 518 & 512 & $502^{h}$ & 491 \\
\hline${ }^{m} D_{28}\left(b_{1}\right)$ & 19 & 433 & 433 & $458^{k}$ & 452 & $454^{\mathrm{e}}$ & 455 & 433 & 432 & 433 & 426 & 417 & 418 \\
\hline${ }^{m} D_{29}\left(a_{2}\right)$ & 14 & $226^{g}$ & 216 & $243^{\mathrm{k}}$ & 228 & $252^{\mathrm{e}}$ & 239 & $212^{\mathrm{g}}$ & 197 & $199^{g}$ & 180 & $186^{\mathrm{h}}$ & 165 \\
\hline${ }^{m} D_{30}\left(b_{1}\right)$ & 20 & 204 & 194 & $200^{\mathrm{k}}$ & 217 & $227^{\mathrm{e}}$ & 222 & 175 & 162 & 132 & 140 & 98 & 123 \\
\hline
\end{tabular}

${ }^{a}$ Infrared spectroscopy of the liquid unless otherwise indicated [20].

${ }^{\mathrm{b}}$ B3LYP/aug-cc-pVTZ values scaled by 0.97 - this work (see text). For consistency with the following tables, we have noted the symmetric and asymmetric stretch nature of $D_{10}$ and $D_{13}$ as well as the $D_{18}$ and $D_{19}$ explicitly. The conformer used for $m \mathrm{Xyl}$ has both methyl groups eclipsed with respect to the phenyl ring, and rotated $180 \square$ with respect to each other ("trans"). For resorcinol, the $\mathrm{OH}$ groups are in the plane of the phenyl ring, in a pseudo hydrogen-bonded arrangement.

${ }^{\mathrm{c}}$ Wilson jet cooled dispersed fluorescence.

${ }^{\mathrm{d}}$ Experimental values from a jet-cooled dispersed fluorescence study [35].

${ }^{\mathrm{e}} \mathrm{A}$ number of experimental values were derived by us from assignments and band positions given in the jet-cooled dispersed fluorescence study [28].

${ }^{\mathrm{fj} j}$ Poor agreement of the experimental value [21] with the calculated values leads us to conclude the experimental assignment was incorrect.

${ }^{\mathrm{g}}$ Raman studies of the liquid [21].

${ }^{\mathrm{h}}$ Infrared values via the solid state [21].

${ }^{\mathrm{i}}$ Wavenumber ordering switched from Ref. [21]. 
${ }^{\mathrm{j}}$ Inferred values from Ref. [21].

${ }^{\mathrm{k}}$ From a summary of values used in thermochemical study by Kudchadker et al. [30]. 
Table 3. Vibrational wavenumber for $m-\mathrm{C}_{6} \mathrm{H}_{4} \mathrm{XY}$ : asymmetric meta-diahalobenzenes

\begin{tabular}{|c|c|c|c|c|c|c|c|c|c|c|c|c|}
\hline \multirow{2}{*}{ Mode } & \multicolumn{2}{|c|}{$m \mathrm{ClFB}$} & \multicolumn{2}{|c|}{$m \mathrm{BrFB}$} & \multicolumn{2}{|c|}{$m \mathrm{FIB}$} & \multicolumn{2}{|c|}{$m \mathrm{BrClB}$} & \multicolumn{2}{|c|}{$m$ ClIB } & \multicolumn{2}{|c|}{$\mathrm{mBrIB}$} \\
\hline & $\operatorname{Expt}^{\mathrm{a}}$ & $\mathrm{Calc}^{\mathrm{b}}$ & Expt $^{a}$ & $\mathrm{Calc}^{\mathrm{b}}$ & Expt $^{\mathrm{a}}$ & $\mathrm{Calc}^{\mathrm{b}}$ & $\operatorname{Expt}^{\mathrm{a}}$ & $\mathrm{Calc}^{\mathrm{b}}$ & $\operatorname{Expt}^{\mathrm{a}}$ & $\mathrm{Calc}^{\mathrm{b}}$ & $\operatorname{Expt}^{\mathrm{a}}$ & Calc $^{\mathrm{b}}$ \\
\hline \multicolumn{13}{|c|}{$a^{\prime}$} \\
\hline$D_{1}$ & - & 3122 & 3096 & 3120 & 3085 & 3117 & 3090 & 3122 & 3080 & 3120 & 3075 & 3117 \\
\hline$D_{2}$ & 3095 & 3116 & 3073 & 3115 & 3064 & 3113 & 3064 & 3115 & 3065 & 3113 & 3060 & 3112 \\
\hline$D_{3}$ & - & 3112 & - & 3110 & - & 3109 & $3049^{d}$ & 3111 & 3056 & 3109 & 3051 & 3107 \\
\hline$D_{4}$ & - & 3089 & - & 3087 & - & 3085 & - & 3085 & - & 3084 & - & 3082 \\
\hline$D_{5}$ & 1598 & 1581 & 1595 & 1578 & 1584 & 1574 & 1575 & 1560 & 1565 & 1556 & 1566 & 1552 \\
\hline$D_{6}$ & 1595 & 1578 & 1575 & 1573 & 1567 & 1568 & 1575 & 1556 & 1551 & 1551 & 1559 & 1547 \\
\hline$D_{7}$ & 1475 & 1463 & 1477 & 1460 & 1468 & 1458 & 1462 & 1448 & 1456 & 1446 & 1454 & 1442 \\
\hline$D_{8}$ & 1439 & 1417 & 1431 & 1413 & 1421 & 1408 & 1411 & 1395 & 1403 & 1391 & 1405 & 1388 \\
\hline$D_{9}$ & 1296 & 1296 & 1292 & 1294 & 1293 & 1291 & 1288 & 1288 & 1291 & 1289 & 1290 & 1287 \\
\hline$D_{10}$ & $\begin{array}{l}1224^{\mathrm{e}} \\
(\mathrm{C}-\mathrm{F})\end{array}$ & $\begin{array}{c}1203 \\
(\mathrm{C}-\mathrm{F}) \\
\end{array}$ & $\begin{array}{l}1220^{\mathrm{e}} \\
(\mathrm{C}-\mathrm{F})\end{array}$ & $\begin{array}{l}1200^{\mathrm{e}} \\
(\mathrm{C}-\mathrm{F})\end{array}$ & $\begin{array}{l}\begin{array}{l}1214^{\mathrm{e}} \\
(\mathrm{C}-\mathrm{F})\end{array} \\
\end{array}$ & $\begin{array}{l}1198^{\mathrm{e}} \\
(\mathrm{C}-\mathrm{F})\end{array}$ & $\begin{array}{l}1063^{\mathrm{e}} \\
(\mathrm{sym})\end{array}$ & $\begin{array}{l}1053^{\mathrm{e}} \\
(\mathrm{sym})\end{array}$ & $\begin{array}{l}1058^{\mathrm{e}} \\
(\mathrm{sym})\end{array}$ & $\begin{array}{l}1046^{\mathrm{e}} \\
(\mathrm{sym})\end{array}$ & $\begin{array}{l}1059^{\mathrm{e}} \\
(\mathrm{sym})\end{array}$ & $\begin{array}{l}1037^{\mathrm{e}} \\
\text { (sym) }\end{array}$ \\
\hline$D_{11}$ & $1263^{\mathrm{e}}$ & 1254 & $1266^{\mathrm{e}}$ & 1255 & $1264^{\mathrm{e}}$ & 1255 & $1260^{\mathrm{e}}$ & 1252 & $1255^{\mathrm{e}}$ & 1252 & $1253^{\mathrm{e}}$ & $1251^{\mathrm{e}}$ \\
\hline$D_{12}$ & $1155^{\mathrm{e}}$ & 1143 & $1157^{\mathrm{e}}$ & 1144 & $1158^{\mathrm{e}}$ & 1147 & $1165^{\mathrm{e}}$ & 1154 & $1164^{\mathrm{e}}$ & 1157 & $1165^{\mathrm{e}}$ & $1158^{\mathrm{e}}$ \\
\hline$D_{13}$ & $\begin{array}{l}1059^{\mathrm{e}} \\
(\mathrm{C}-\mathrm{Cl})\end{array}$ & $\begin{array}{c}1049 \\
(\mathrm{C}-\mathrm{Cl})\end{array}$ & $\begin{array}{l}1057^{\mathrm{e}} \\
(\mathrm{C}-\mathrm{Br})\end{array}$ & $\begin{array}{c}1043 \\
(\mathrm{C}-\mathrm{Br})\end{array}$ & $\begin{array}{l}\begin{array}{l}1051^{\mathrm{e}} \\
(\mathrm{C}-\mathrm{I})\end{array} \\
\end{array}$ & $\begin{array}{l}1039 \\
(\mathrm{C}-\mathrm{I})\end{array}$ & $\begin{array}{c}1082^{\mathrm{e}} \\
\text { (asym) }\end{array}$ & $\begin{array}{c}1067 \\
\text { (asym) }\end{array}$ & $\begin{array}{l}1078^{\mathrm{e}} \\
\text { (asym) }\end{array}$ & $\begin{array}{c}1070 \\
\text { (asym) }\end{array}$ & $\begin{array}{c}1078^{\mathrm{e}} \\
(\text { asym) }\end{array}$ & $\begin{array}{l}1064^{\mathrm{e}} \\
\text { (asym) }^{2}\end{array}$ \\
\hline$D_{14}$ & $1080^{\mathrm{e}}$ & 1072 & $1081^{\mathrm{e}}$ & 1073 & $1079^{\mathrm{e}}$ & 1074 & $1106^{\mathrm{e}}$ & 1089 & $1096^{\mathrm{e}}$ & 1088 & $1086^{\mathrm{e}}$ & $1085^{\mathrm{e}}$ \\
\hline$D_{15}$ & 1002 & 991 & 1001 & 989 & 1000 & 988 & 997 & 985 & 990 & 983 & 998 & 980 \\
\hline$D_{16}$ & 880 & 865 & $859^{\mathrm{d}}$ & 846 & 846 & 834 & 753 & 734 & 742 & 724 & 711 & 695 \\
\hline$D_{17}$ & 683 & 673 & 666 & 656 & 649 & 646 & 650 & 645 & 648 & 640 & 643 & 634 \\
\hline$D_{18}$ & $\begin{array}{c}519 \\
(\mathrm{C}-\mathrm{F}) \\
\end{array}$ & $\begin{array}{c}510 \\
(\mathrm{C}-\mathrm{F}) \\
\end{array}$ & $\begin{array}{c}519 \\
(\mathrm{C}-\mathrm{F}) \\
\end{array}$ & $\begin{array}{c}510 \\
(\mathrm{C}-\mathrm{F}) \\
\end{array}$ & $\begin{array}{c}518 \\
(\mathrm{C}-\mathrm{F}) \\
\end{array}$ & $\begin{array}{c}510 \\
(\mathrm{C}-\mathrm{F}) \\
\end{array}$ & $\begin{array}{c}304^{\mathrm{f}} \\
(\mathrm{sym})\end{array}$ & $\begin{array}{c}294 \\
\text { (sym) }\end{array}$ & $\begin{array}{c}256^{\mathrm{f}} \\
(\mathrm{sym})\end{array}$ & $\begin{array}{c}251 \\
(\mathrm{sym})\end{array}$ & $\begin{array}{c}250^{\mathrm{f}} \\
(\mathrm{sym})\end{array}$ & $\begin{array}{c}242 \\
\text { (sym) }\end{array}$ \\
\hline$D_{19}$ & $\begin{array}{c}409^{\mathrm{f}} \\
(\mathrm{C}-\mathrm{Cl})\end{array}$ & $\begin{array}{c}394 \\
(\mathrm{C}-\mathrm{Cl})\end{array}$ & $\begin{array}{c}307^{\mathrm{f}} \\
(\mathrm{C}-\mathrm{Br})\end{array}$ & $\begin{array}{c}299 \\
(\mathrm{C}-\mathrm{Br})\end{array}$ & $\begin{array}{l}255^{\mathrm{f}} \\
(\mathrm{C}-\mathrm{I})\end{array}$ & $\begin{array}{c}252 \\
(\mathrm{C}-\mathrm{I})\end{array}$ & $\begin{array}{c}422^{\mathrm{f}} \\
\text { (asym) }\end{array}$ & $\begin{array}{c}406 \\
\text { (asym) }\end{array}$ & $\begin{array}{c}424^{\mathrm{f}} \\
\text { (asym) }\end{array}$ & $\begin{array}{c}405 \\
\text { (asym) }\end{array}$ & $\begin{array}{c}339^{\mathrm{f}} \\
(\text { asym) }\end{array}$ & $\begin{array}{c}329 \\
\text { (asym) }\end{array}$ \\
\hline$D_{20}$ & $444^{\mathrm{df}}$ & 433 & $436^{f}$ & 425 & $439^{f}$ & 419 & $352^{\mathrm{f}}$ & 343 & $340^{\mathrm{f}}$ & 332 & $297^{\mathrm{f}}$ & 290 \\
\hline$D_{21}$ & $245^{\mathrm{d}}$ & 238 & 203 & 196 & 177 & 169 & $-g$ & 155 & 150 & 136 & $-g$ & 106 \\
\hline \multicolumn{13}{|c|}{$a^{\prime \prime}$} \\
\hline$D_{22}$ & 965 & 967 & 966 & 966 & 968 & 966 & 968 & 971 & 968 & 971 & 970 & 971 \\
\hline$D_{23}$ & $890^{\mathrm{c}}$ & 883 & 882 & 885 & 888 & 888 & 894 & 894 & 895 & 897 & 898 & 898 \\
\hline$D_{24}$ & 858 & 864 & 858 & 862 & 860 & 862 & 872 & 874 & 868 & 876 & 870 & 874 \\
\hline$D_{26}$ & 774 & 772 & 773 & 770 & 773 & 770 & 775 & 771 & 771 & 770 & 769 & 768 \\
\hline$D_{25}$ & 672 & 673 & 671 & 671 & 672 & 669 & 674 & 671 & 672 & 671 & 670 & 668 \\
\hline$D_{27}$ & 565 & 566 & 554 & 554 & 542 & 544 & $515^{\mathrm{d}}$ & 522 & 510 & 512 & 499 & 501 \\
\hline$D_{28}$ & 443 & 443 & 440 & 439 & 430 & 435 & 430 & 428 & 420 & 425 & 420 & 420 \\
\hline$D_{29}$ & 245 & 233 & 241 & 231 & 235 & 231 & 202 & 191 & 200 & 187 & $200^{c}$ & 174 \\
\hline$D_{30}$ & 189 & 177 & 174 & 158 & 161 & 142 & 163 & 148 & 144 & 136 & 114 & 128 \\
\hline
\end{tabular}

${ }^{a}$ Infrared spectroscopy of the liquid unless otherwise indicated [21].

${ }^{\mathrm{b}}$ B3LYP/aug-cc-pVTZ values scaled by 0.97 - this work (see text). For consistency with the following tables, we have noted the symmetric and asymmetric stretch nature of $D_{10}$ and $D_{13}$ as well as the $D_{18}$ and $D_{19}$ explicitly.

${ }^{\mathrm{c}}$ Inferred values from Ref. [21].

${ }^{\mathrm{d}}$ Raman studies of liquid from Ref. [21].

e Some of the vibrations $D_{10}-D_{14}$ do not appear in the same wavenumber order as in $m$ DFB. Vibrations that have similar motions have been given the same $D_{i}$ label, and the experimental wavenumbers have been re-ordered to match this.

${ }^{\mathrm{f}}$ Some of the vibrations $D_{18}-D_{20}$ do not appear in the same wavenumber order as in $m \mathrm{DFB}$. Vibrations that have similar motions have been given the same $D_{i}$ label, and the experimental wavenumbers have been re-ordered to match this.

g Poor agreement of the experimental value with the calculated values leads us to conclude the experimental assignment is incorrect. 
Table 4. Vibrational wavenumber for $m-\mathrm{C}_{6} \mathrm{H}_{4} \mathrm{XCH}$ : meta-halotoluenes

\begin{tabular}{|c|c|c|c|c|c|c|c|c|}
\hline \multirow[t]{2}{*}{ Mode } & \multicolumn{2}{|c|}{$m \mathrm{FT}$} & \multicolumn{2}{|c|}{$m \mathrm{ClT}$} & \multicolumn{2}{|c|}{$m \mathrm{BrT}$} & \multicolumn{2}{|c|}{$m \mathrm{IT}$} \\
\hline & $\operatorname{Expt}^{\mathrm{a}}$ & $\mathrm{Calc}^{\mathrm{b}}$ & $\mathrm{Expt}^{\mathrm{a}}$ & $\mathrm{Calc}^{\mathrm{b}}$ & $\operatorname{Expt}^{\mathrm{a}}$ & $\mathrm{Calc}^{\mathrm{b}}$ & $\operatorname{Expt}^{\mathrm{a}}$ & $\mathrm{Calc}^{\mathrm{b}}$ \\
\hline \multicolumn{9}{|c|}{$a^{\prime}$} \\
\hline$D_{1}$ & 3081 & 3108 & 3085 & 3109 & 3109 & 3109 & 3080 & 3108 \\
\hline$D_{2}$ & 3060 & 3089 & 3064 & 3091 & 3090 & 3090 & 3058 & 3088 \\
\hline$D_{3}$ & & 3087 & & 3086 & 3085 & 3085 & & 3084 \\
\hline$D_{4}$ & & 3072 & & 3070 & 3069 & 3069 & & 3068 \\
\hline$D_{5}$ & 1595 & 1578 & 1578 & 1562 & 1557 & 1557 & 1564 & 1552 \\
\hline$D_{6}$ & 1623 & 1602 & 1604 & 1587 & 1585 & 1585 & 1593 & 1581 \\
\hline$D_{7}$ & 1492 & 1479 & 1478 & 1468 & 1466 & 1466 & 1466 & 1464 \\
\hline$D_{8}$ & 1460 & 1419 & 1467 & 1403 & 1402 & 1402 & 1416 & 1397 \\
\hline$D_{9}$ & 1295 & 1302 & 1296 & 1299 & 1298 & 1298 & 1300 & 1300 \\
\hline$D_{10}$ & $\begin{array}{l}1251^{\mathrm{c}} \\
(\mathrm{sym})\end{array}$ & $\begin{array}{c}1240 \\
\text { (sym) }\end{array}$ & $\begin{array}{c}1221^{\mathrm{c}} \\
(\mathrm{C}-\mathrm{Me})\end{array}$ & $\begin{array}{c}1194 \\
(\mathrm{C}-\mathrm{Me})\end{array}$ & $\begin{array}{c}1192^{\mathrm{c}} \\
(\mathrm{C}-\mathrm{Me})\end{array}$ & $\begin{array}{c}1192 \\
(\mathrm{C}-\mathrm{Me})\end{array}$ & $\begin{array}{l}1211^{\mathrm{c}} \\
(\mathrm{C}-\mathrm{Me})\end{array}$ & $\begin{array}{c}1191 \\
(\mathrm{C}-\mathrm{Me})\end{array}$ \\
\hline$D_{11}$ & $1266^{\mathrm{c}}$ & 1271 & $1272^{\mathrm{c}}$ & 1267 & $1268^{\mathrm{c}}$ & 1268 & $1262^{\mathrm{c}}$ & 1266 \\
\hline$D_{12}$ & 1160 & 1148 & 1164 & 1155 & 1157 & 1157 & 1168 & 1159 \\
\hline$D_{13}$ & $\begin{array}{c}1143 \\
\text { (asym) }\end{array}$ & $\begin{array}{c}1127 \\
\text { (asym) }\end{array}$ & $\begin{array}{c}1096 \\
(\mathrm{C}-\mathrm{Cl})\end{array}$ & $\begin{array}{c}1086 \\
(\mathrm{C}-\mathrm{Cl})\end{array}$ & $\begin{array}{l}1060^{\mathrm{c}} \\
(\mathrm{C}-\mathrm{Br})\end{array}$ & $\begin{array}{c}1060 \\
(\mathrm{C}-\mathrm{Br})\end{array}$ & $\begin{array}{l}1063^{\mathrm{c}} \\
(\mathrm{C}-\mathrm{I})\end{array}$ & $\begin{array}{l}1054 \\
\text { (C-I) }\end{array}$ \\
\hline$D_{14}$ & 1079 & 1071 & 1079 & 1068 & $1089^{c}$ & 1089 & $1093^{c}$ & 1091 \\
\hline$D_{15}$ & 1003 & 989 & 1002 & 990 & 988 & 988 & 992 & 986 \\
\hline$D_{16}$ & 924 & 913 & 858 & 837 & 819 & 819 & 819 & 809 \\
\hline$D_{17}$ & 728 & 719 & 684 & 673 & 659 & 659 & 657 & 651 \\
\hline$D_{18}$ & $\begin{array}{c}527 \\
\text { (sym) }\end{array}$ & $\begin{array}{c}519 \\
\text { (sym) }\end{array}$ & $\begin{array}{c}522 \\
(\mathrm{C}-\mathrm{Me}) \\
\end{array}$ & $\begin{array}{c}511 \\
(\mathrm{C}-\mathrm{Me}) \\
\end{array}$ & $\begin{array}{c}508 \\
(\mathrm{C}-\mathrm{Me}) \\
\end{array}$ & $\begin{array}{c}508 \\
(\mathrm{C}-\mathrm{Me}) \\
\end{array}$ & $\begin{array}{c}521 \\
(\mathrm{C}-\mathrm{Me}) \\
\end{array}$ & $\begin{array}{c}502 \\
(\mathrm{C}-\mathrm{Me}) \\
\end{array}$ \\
\hline$D_{19}$ & $\begin{array}{c}513 \\
(\text { asym) }\end{array}$ & $\begin{array}{c}505 \\
\text { (asym) }\end{array}$ & $\begin{array}{c}416 \\
(\mathrm{C}-\mathrm{Cl})\end{array}$ & $\begin{array}{c}402 \\
(\mathrm{C}-\mathrm{Cl})\end{array}$ & $\begin{array}{c}299^{\mathrm{d}} \\
(\mathrm{C}-\mathrm{Br})\end{array}$ & $\begin{array}{c}299 \\
(\mathrm{C}-\mathrm{Br})\end{array}$ & $\begin{array}{l}255^{\mathrm{d}} \\
(\mathrm{C}-\mathrm{I})\end{array}$ & $\begin{array}{c}252 \\
(\mathrm{C}-\mathrm{I}) \\
\end{array}$ \\
\hline$D_{20}$ & $450^{\mathrm{e}}$ & 435 & 387 & 376 & $372^{\mathrm{d}}$ & 372 & $371^{\mathrm{d}}$ & 362 \\
\hline$D_{21}$ & 296 & 285 & 221 & 226 & 190 & 190 & 173 & 166 \\
\hline \multicolumn{9}{|c|}{$a^{\prime \prime}$} \\
\hline$D_{22}$ & 970 & 968 & 976 & 972 & 969 & 972 & 970 & 973 \\
\hline$D_{23}$ & 886 & 886 & 898 & 895 & 896 & 896 & 896 & 897 \\
\hline$D_{24}$ & 858 & 860 & 869 & 870 & 868 & 872 & 873 & 875 \\
\hline$D_{25}$ & 778 & 774 & 776 & 772 & 770 & 769 & 768 & 767 \\
\hline$D_{26}$ & 683 & 683 & 684 & 683 & 680 & 682 & 681 & 681 \\
\hline$D_{27}$ & 556 & 557 & $522^{\mathrm{f}}$ & 526 & 513 & 519 & 515 & 515 \\
\hline$D_{28}$ & 442 & 443 & 431 & 433 & 429 & 430 & 424 & 426 \\
\hline$D_{29}$ & 243 & 235 & 234 & 208 & 220 & 207 & 218 & 205 \\
\hline$D_{30}$ & 212 & 198 & 185 & 173 & 171 & 157 & 157 & 141 \\
\hline
\end{tabular}

${ }^{a}$ Infrared spectroscopy of the liquid unless otherwise indicated [21].

${ }^{\text {b } B 3 L Y P / a u g-c c-p V T Z ~ v a l u e s ~ s c a l e d ~ b y ~} 0.97$ - this work (see text). For consistency with the following tables, we have noted the symmetric and asymmetric stretch nature of $D_{10}$ and $D_{13}$ as well as the $D_{18}$ and $D_{19}$ explicitly. The conformer employed for $m \mathrm{FT}$ was eclipsed, while for the other three species it was staggered.

${ }^{c}$ Note that some of the vibrations $D_{10}-D_{14}$ are not in the same wavenumber order as in $m$ DFB. Vibrations with similar motions have been assigned the same $D_{i}$ label. The corresponding experimental wavenumbers have been reordered to match the calculated ordering. 
${ }^{d}$ Note that some of the vibrations $D_{18}-D_{19}$ are not in the same wavenumber order as in $m$ DFB. Vibrations with similar motions have been assigned the same $D_{i}$ label. The corresponding experimental wavenumbers have been reordered to match the calculated ordering.

${ }^{\mathrm{e}}$ Raman values of the liquid from Ref. [21].

${ }^{\mathrm{f}}$ Inferred value from Ref. [21]. 
Table 5. Vibrational wavenumber for $m-\mathrm{C}_{6} \mathrm{H}_{4} \mathrm{XOH}$ : meta-halophenols and meta-cresol

\begin{tabular}{|c|c|c|c|c|c|c|c|c|c|c|}
\hline Mode & \multicolumn{2}{|c|}{$m$-cresol } & \multicolumn{2}{|c|}{$m \mathrm{FPhOH}$} & \multicolumn{2}{|c|}{$m \mathrm{ClPhOH}$} & \multicolumn{2}{|c|}{$m \mathrm{BrPhOH}$} & \multicolumn{2}{|c|}{$m \mathrm{IPhOH}$} \\
\hline & $\operatorname{Expt}^{\mathrm{a}}$ & $\mathrm{Calc}^{\mathrm{b}}$ & $\mathrm{Expt}^{\mathrm{a}}$ & $\mathrm{Calc}^{\mathrm{b}}$ & $\operatorname{Expt}^{\mathrm{a}}$ & $\mathrm{Calc}^{\mathrm{b}}$ & $\operatorname{Expt}^{\mathrm{a}}$ & $\mathrm{Calc}^{\mathrm{b}}$ & $\operatorname{Expt}^{\mathrm{a}}$ & $\mathrm{Calc}^{\mathrm{b}}$ \\
\hline \multicolumn{11}{|c|}{$a^{\prime}$} \\
\hline$D_{1}$ & 3080 & 3088 & 3074 & 3116 & 3057 & 3115 & 3054 & 3115 & 3052 & 3113 \\
\hline$D_{2}$ & 3042 & 3082 & 3049 & 3115 & 3073 & 3116 & 3072 & 3116 & 3073 & 3114 \\
\hline$D_{3}$ & - & 3071 & - & 3090 & - & 3088 & - & 3087 & - & 3086 \\
\hline$D_{4}$ & - & 3058 & - & 3067 & - & 3065 & - & 3065 & - & 3065 \\
\hline$D_{5}$ & 1600 & 1579 & $1603^{\mathrm{e}}$ & 1593 & $1599^{\mathrm{e}}$ & 1577 & $1584^{\mathrm{e}}$ & 1574 & $1578^{\mathrm{e}}$ & 1569 \\
\hline$D_{6}$ & 1614 & 1606 & $1619^{\mathrm{e}}$ & 1602 & $1608^{\mathrm{e}}$ & 1588 & $1599^{\mathrm{e}}$ & 1583 & $1595^{\mathrm{e}}$ & 1579 \\
\hline$D_{7}$ & 1490 & 1480 & 1491 & 1475 & 1489 & 1464 & 1484 & 1461 & 1480 & 1459 \\
\hline$D_{8}$ & 1462 & 1470 & 1461 & 1466 & 1462 & 1447 & 1455 & 1443 & 1438 & 1439 \\
\hline$D_{9}$ & $1281^{\mathrm{e}}$ & 1299 & 1307 & 1312 & 1310 & 1303 & 1311 & 1299 & 1310 & 1298 \\
\hline$D_{10}$ & $\begin{array}{c}1268^{\mathrm{e}} \\
(\mathrm{C}-\mathrm{OH})\end{array}$ & $\begin{array}{c}1261 \\
(\mathrm{C}-\mathrm{OH})\end{array}$ & $\begin{array}{l}1282^{\mathrm{e}} \\
(\mathrm{sym})\end{array}$ & $\begin{array}{l}1267 \\
(\mathrm{sym})\end{array}$ & $\begin{array}{c}1258^{\mathrm{e}} \\
(\mathrm{C}-\mathrm{OH})\end{array}$ & $\begin{array}{c}1238 \\
(\mathrm{C}-\mathrm{OH})\end{array}$ & $\begin{array}{c}1246^{\mathrm{e}} \\
(\mathrm{C}-\mathrm{OH})\end{array}$ & $\begin{array}{c}1235 \\
(\mathrm{C}-\mathrm{OH})\end{array}$ & $\begin{array}{c}1246^{\mathrm{e}} \\
(\mathrm{C}-\mathrm{OH})\end{array}$ & $\begin{array}{c}1235 \\
(\mathrm{C}-\mathrm{OH})\end{array}$ \\
\hline$D_{11}$ & $1306^{\mathrm{e}}$ & 1307 & $1295^{\mathrm{e}}$ & 1286 & $1290^{\mathrm{e}}$ & 1286 & $1294^{\mathrm{e}}$ & 1286 & $1293^{\mathrm{e}}$ & 1286 \\
\hline$D_{12}$ & 1163 & 1149 & 1154 & 1144 & 1154 & 1148 & 1154 & 1156 & 1157 & 1148 \\
\hline$D_{13}$ & $\begin{array}{c}1149 \\
(\mathrm{C}-\mathrm{Me})\end{array}$ & $\begin{array}{c}1138 \\
(\mathrm{C}-\mathrm{Me})\end{array}$ & $\begin{array}{c}1134 \\
\text { (asym) }\end{array}$ & $\begin{array}{c}1112 \\
\text { (asym) }\end{array}$ & $\begin{array}{l}1069^{\mathrm{e}} \\
(\mathrm{C}-\mathrm{Cl})\end{array}$ & $\begin{array}{c}1057 \\
(\mathrm{C}-\mathrm{Cl})\end{array}$ & $\begin{array}{l}1062^{\mathrm{e}} \\
(\mathrm{C}-\mathrm{Br})\end{array}$ & $\begin{array}{c}1050 \\
(\mathrm{C}-\mathrm{Br})\end{array}$ & $\begin{array}{c}1056^{\mathrm{e}} \\
(\mathrm{C}-\mathrm{I})\end{array}$ & $\begin{array}{l}1046 \\
\text { (C-I) }\end{array}$ \\
\hline$D_{14}$ & 1085 & 1080 & 1072 & 1064 & $1088^{\mathrm{e}}$ & 1076 & $1083^{\mathrm{e}}$ & 1077 & $1082^{\mathrm{e}}$ & 1079 \\
\hline$D_{15}$ & 1000 & 986 & 1004 & 989 & 998 & 984 & 996 & 983 & 994 & 981 \\
\hline$D_{16}$ & 930 & 918 & 954 & 943 & 888 & 870 & 864 & 851 & 851 & 840 \\
\hline$D_{17}$ & 733 & 722 & 738 & 729 & 687 & 676 & 667 & 659 & 653 & 651 \\
\hline$D_{18}$ & $\begin{array}{c}536 \\
(\mathrm{C}-\mathrm{OH}) \\
\end{array}$ & $\begin{array}{c}530 \\
(\mathrm{C}-\mathrm{OH}) \\
\end{array}$ & $\begin{array}{c}530 \\
(\mathrm{sym})\end{array}$ & $\begin{array}{c}523 \\
\text { (sym) }\end{array}$ & $\begin{array}{c}526 \\
(\mathrm{C}-\mathrm{OH}) \\
\end{array}$ & $\begin{array}{c}521 \\
(\mathrm{C}-\mathrm{OH}) \\
\end{array}$ & $\begin{array}{c}531 \\
(\mathrm{C}-\mathrm{OH}) \\
\end{array}$ & $\begin{array}{c}521 \\
(\mathrm{C}-\mathrm{OH}) \\
\end{array}$ & $\begin{array}{c}529 \\
(\mathrm{C}-\mathrm{OH}) \\
\end{array}$ & $\begin{array}{c}521 \\
(\mathrm{C}-\mathrm{OH}) \\
\end{array}$ \\
\hline$D_{19}$ & $\begin{array}{c}518 \\
(\mathrm{C}-\mathrm{Me})\end{array}$ & $\begin{array}{c}508 \\
(\mathrm{C}-\mathrm{Me})\end{array}$ & $\begin{array}{c}515 \\
(\text { asym) }\end{array}$ & $\begin{array}{c}506 \\
\text { (asym) }\end{array}$ & $\begin{array}{c}410^{\mathrm{f}} \\
(\mathrm{C}-\mathrm{Cl})\end{array}$ & $\begin{array}{c}395 \\
(\mathrm{C}-\mathrm{Cl})\end{array}$ & $\begin{array}{c}308^{\mathrm{f}} \\
(\mathrm{C}-\mathrm{Br})\end{array}$ & $\begin{array}{c}298 \\
(\mathrm{C}-\mathrm{Br})\end{array}$ & $\begin{array}{l}255^{\mathrm{cf}} \\
(\mathrm{C}-\mathrm{I})\end{array}$ & $\begin{array}{c}252 \\
(\mathrm{C}-\mathrm{I})\end{array}$ \\
\hline$D_{20}$ & 443 & 434 & 474 & 464 & $442^{\mathrm{c}, \mathrm{f}}$ & 431 & $439^{f}$ & 423 & $433^{f}$ & 435 \\
\hline$D_{21}$ & 297 & 288 & 327 & 321 & 249 & 240 & 206 & 197 & 178 & 172 \\
\hline \multicolumn{11}{|c|}{$a^{\prime \prime}$} \\
\hline$D_{22}$ & 962 & 959 & 978 & 954 & 962 & 956 & 963 & 957 & 961 & 957 \\
\hline$D_{23}$ & 880 & 850 & $890^{c}$ & 847 & 885 & 859 & 878 & 859 & 867 & 860 \\
\hline$D_{24}$ & 855 & 874 & 849 & 858 & 859 & 865 & $864^{c}$ & 866 & $859^{c}$ & 870 \\
\hline$D_{25}$ & 776 & 765 & 766 & 757 & 771 & 761 & 771 & 760 & 771 & 761 \\
\hline$D_{26}$ & 685 & 686 & 676 & 675 & 676 & 675 & 676 & 674 & 675 & 674 \\
\hline$D_{27}$ & 560 & 564 & $590^{c}$ & 606 & $526^{\mathrm{c}}$ & 574 & $531^{\mathrm{c}}$ & 563 & $529^{c}$ & 552 \\
\hline$D_{28}$ & 443 & 443 & 454 & 455 & 442 & 442 & 435 & 439 & 429 & 435 \\
\hline$D_{29}$ & 246 & 225 & 241 & 234 & 233 & 225 & 231 & 224 & 231 & 223 \\
\hline$D_{30}$ & 211 & 199 & 226 & 218 & 189 & 178 & 170 & 159 & 157 & 143 \\
\hline
\end{tabular}

${ }^{a}$ Infrared spectroscopy of the solution unless otherwise indicated [37].

${ }^{\mathrm{b}}$ B3LYP/aug-cc-pVTZ values scaled by 0.97 - this work (see text). For consistency with the following tables, we have noted the symmetric and asymmetric stretch nature of $D_{10}$ and $D_{13}$ as well as the $D_{18}$ and $D_{19}$ explicitly. For $m$-fluorophenol the conformer was trans, with the $\mathrm{OH}$ pointing away from the halogen. For $m$-chloro-, $m$-bromoand $m$-iodophenol the conformer was $c i s$, with the $\mathrm{OH}$ pointing towards the halogen. For $m$-cresol, the $\mathrm{OH}$ points away from the methyl group, and the latter is staggered with respect to the phenyl ring, with the in-plane $\mathrm{C}-\mathrm{H}$ pointing away from the $\mathrm{O}$ atom.

${ }^{\mathrm{c}}$ Inferred values from Ref. [37].

${ }^{\mathrm{d}}$ Note the vibrations $D_{5}-D_{6}$ are not in the same wavenumber order as in $m$ DFB. Vibrations with similar motions have been assigned the same $D_{i}$ label. The corresponding experimental wavenumbers have been reordered to match the calculated ordering.

${ }^{\text {e }}$ Note that some of the vibrations $D_{9}-D_{14}$ are not in the same wavenumber order as in $m$ DFB. Vibrations with similar motions have been assigned the same $D_{i}$ label. The corresponding experimental wavenumbers have been reordered to match the calculated ordering.

${ }^{\mathrm{f}}$ Note that some of the vibrations $D_{18}-D_{20}$ are not in the same wavenumber order as in $m$ DFB. Vibrations with similar motions have been assigned the same $D_{i}$ label. The corresponding experimental wavenumbers have been reordered to match the calculated ordering. 


\section{Figure Captions}

Figure 1: Generalized Duschinsky matrix showing how the vibrational modes of $m \mathrm{DFB}$ can be expressed in terms of the benzene ones - clearly significant mixing of the benzene modes occurs - see text for further discussion. Black shading indicates a normalized coefficient value of 1.00 , while white indicates a value of 0.00 , with grey shading indicating intermediate values, see text for details.

Figure 2: Generalized Duschinsky matrix showing how the vibrational modes of $m \mathrm{DFB}$ can be expressed in terms of the FBz ones - clearly significant mixing of the fluorobenzene modes occurs see text for further discussion. Black shading indicates a normalized coefficient value of 1.00, while white indicates a value of 0.00 , with grey shading indicating intermediate values, see text for details.

Figure 3: Mass-correlated vibrational wavenumbers showing how the vibrations of benzene (centre) evolve into those of $p \mathrm{DFB}$ (right) and $m \mathrm{DFB}$ (left) for the $a_{1}$ and $b_{2}$ vibrations, according to the indicated axis system. The force field of benzene is employed and the masses of the indicated hydrogen atoms are artificially varied from 1 to $19 \mathrm{amu}$ in each case: ${ }^{19} \mathrm{H}$ in the figure indicates that the mass of the indicated hydrogen atom has been artificially changed to $19 \mathrm{amu}$. The $m$ DFB labels have been included on the left, while on the right hand side the numbers refer to the ${ }^{p} D_{i}$ modes as in Ref. [6]. An expanded region of both of these plots is shown as part of Figure 4, which also gives the Wilson modes in the centre. Note that we have used the same colour scheme and line type as employed in Figure 4.

Figure 4: Mass-correlated vibrational wavenumbers showing how the vibrations of benzene (centre) evolve into those of $p \mathrm{DFB}$ (right) and $m \mathrm{DFB}$ (left) for the vibrations separated into the four $C_{2 v}$ symmetry classes, according to the indicated axis system. The force field of benzene is employed and the masses of the indicated hydrogen atoms are artificially varied from 1 to $19 \mathrm{amu}$ in each case: ${ }^{19} \mathrm{H}$ in the figure indicates that the mass of the indicated hydrogen atom has been artificially changed to 19 amu. The $m$ DFB labels have been included on the left, on the right hand side the numbers refer to the ${ }^{p} D_{i}$ modes from Ref. [6], while the Wilson modes are given in the centre. To aid the reader further, we have also indicated the appropriately colour-coded $D_{2 h}$ symmetry classes on the right-hand side of each panel. To allow comparison with Ref. [6], the purple/red lines indicate $a_{1}$ or $a_{2}$ symmetry vibrations, and blue/green lines indicate $b_{1}$ or $b_{2}$ vibrations, respectively - in each case now referring to the axis system used in that work. Further, vibrations on the right-hand side belong to the $D_{2 h}$ point group and so have $g / u$ symmetry. See text for further discussion.

Figure 5: Generalized Duschinsky matrix showing how the vibrational modes of $m \mathrm{DFB}$ can be expressed in terms of the $p \mathrm{DFB}$ ones, with the molecules aligned as indicated - clearly significant mixing of the modes occurs - see text for further discussion. Black shading indicates a normalized coefficient value of 1.00 , while white indicates a value of 0.00 , with grey shading indicating intermediate values, see text for details. The alignment given allows separation of the modes for both 
molecules into $C_{2 v}$ symmetry blocks, but we have also indicated the $C_{s}$ symmetry partition that is appropriate for asymmetrically-substituted ortho-disubstituted benzenes, and as used for the construction of the ${ }^{\circ} D_{i}$ labels.

Figure 6: Generalized Duschinsky matrix showing how the vibrational modes of $m \mathrm{DFB}$ can be expressed in terms of the $o$ DFB ones, with the molecules aligned in two different ways as indicated clearly significant mixing of the modes occurs in both cases - see text for further discussion. Black shading indicates a normalized coefficient value of 1.00 , while white indicates a value of 0.00 , with grey shading indicating intermediate values, see text for details.

Figure 7: Mass-correlated vibrational wavenumbers showing how the vibrations of $m \mathrm{DFB}$ (left-hand side) evolve as a function of mass in symmetric dihalo species; the highest wavenumber vibrations have been omitted (refer to Table 2). The vibrations have been separated into the two $C_{s}$ symmetry classes, and in each class we have indicated $a$ or $b$ character with colour, as indicated. The force field of $m \mathrm{DFB}$ is employed and the masses of both fluorine atoms are artificially varied from 19 to $127 \mathrm{amu}$ simultaneously in each case, to match the mass of the most abundant, naturally-occurring isotope of the halogens. The numbering of the ${ }^{m} D_{i}$ labels is included on the left. Note that crossings between vibrations of different symmetry is allowed. The data points are the experimental values from Table 2, while the lines are the calculated values using a fixed force field for $m$ DFB and using artificial isotopes.

Figure 8: Mass-correlated vibrational wavenumbers showing how the vibrations of $m \mathrm{DFB}$ (left-hand side) evolve as a function of mass in asymmetric dihalo species; the highest wavenumber vibrations have been omitted (refer to Table 3 ). The vibrations have been separated into the two $C_{s}$ symmetry classes. The force field of $m \mathrm{DFB}$ is employed and the mass of the ortho fluorine atom is artificially varied from 19 to $127 \mathrm{amu}$ in each case, to match the mass of the most abundant, naturally-occurring isotope of the halogens. The numbering of the ${ }^{m} D_{i}$ labels is included on the left. (Note that the theoretical lines do not cross for $D_{10}$ and $D_{11}$, as required; however, the experimental data indicate that there is a switch in the ordering of these two vibrations between $m \mathrm{DFB}$ and the cases where one fluorine atom is replaced by a heavier halogen - this effect is very small, and must be a result of subtle changes in the force field. The actual assignments of the vibrations, however, are based on the atomic motion.) The data points are the experimental values from Table 3, while the lines are the calculated values using a fixed force field for $m \mathrm{DFB}$ and using artificial isotopes.

Figure 9: Calculated vibrational modes for $m$ DFB (B3LYP/aug-cc-pVTZ), labelled using the ${ }^{m} D_{i}$ notation in the present work. See text for details. 
Figure 10: A selection of calculated vibrational modes for $m$ DFB and $m$ FIB (B3LYP/aug-cc-pVTZ), labelled using the ${ }^{m} D_{i}$ notation in the present work. (Green circles represent $\mathrm{F}$ and magenta circles represent I; $\mathrm{C}$ and $\mathrm{H}$ are both open circles.) Note that the $D_{10}$ and $D_{13}$ modes are largely the in-phase and out-of-phase C-F stretches for $m \mathrm{DFB}$, while in $m$ FIB these modes have evolved in being largelylocalized C-F and C-I stretches, respectively; similar comments apply to $D_{18}$ and $D_{19}$. See text for details and discussion. 
Figure 1:

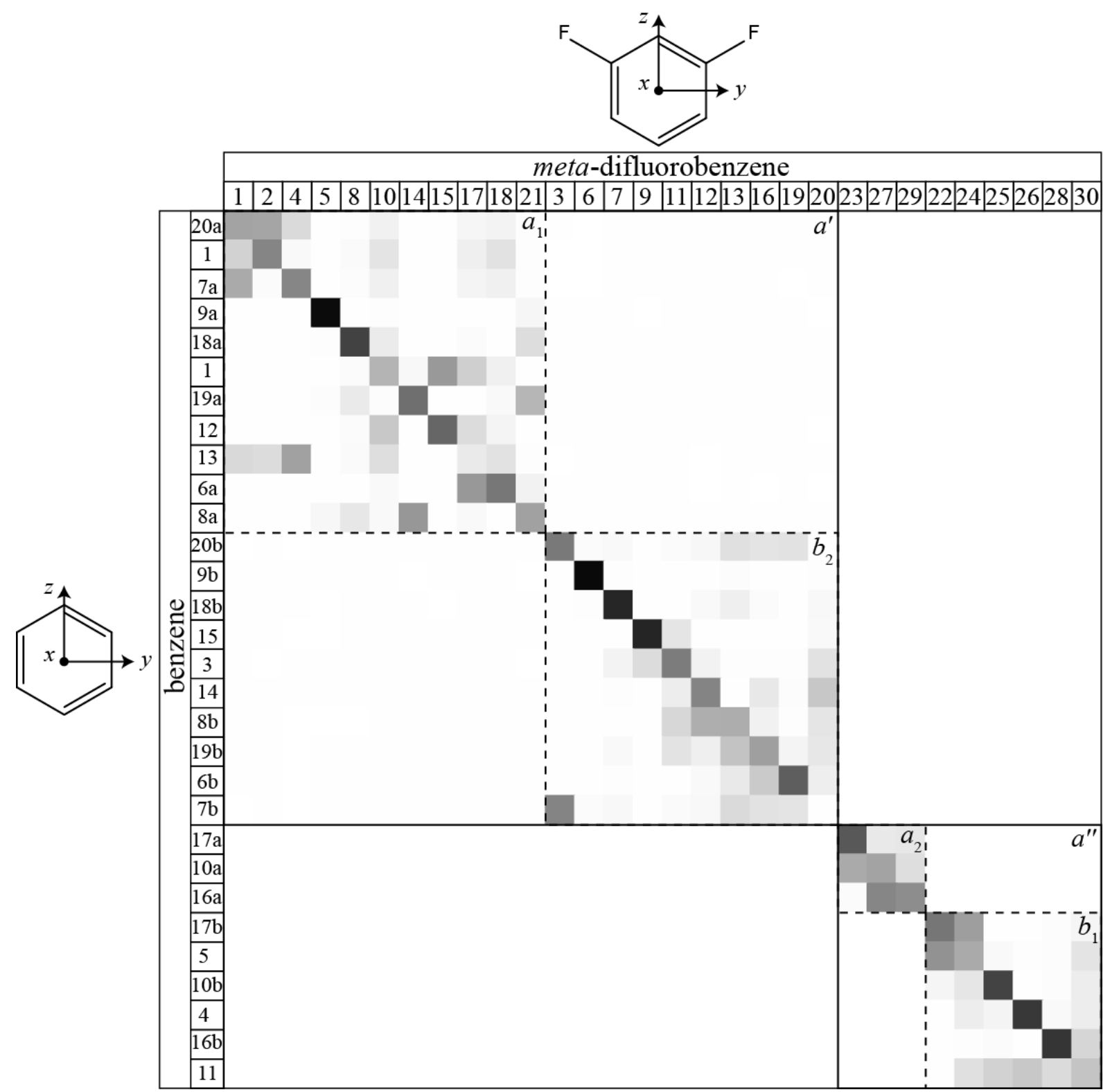


Figure 2:

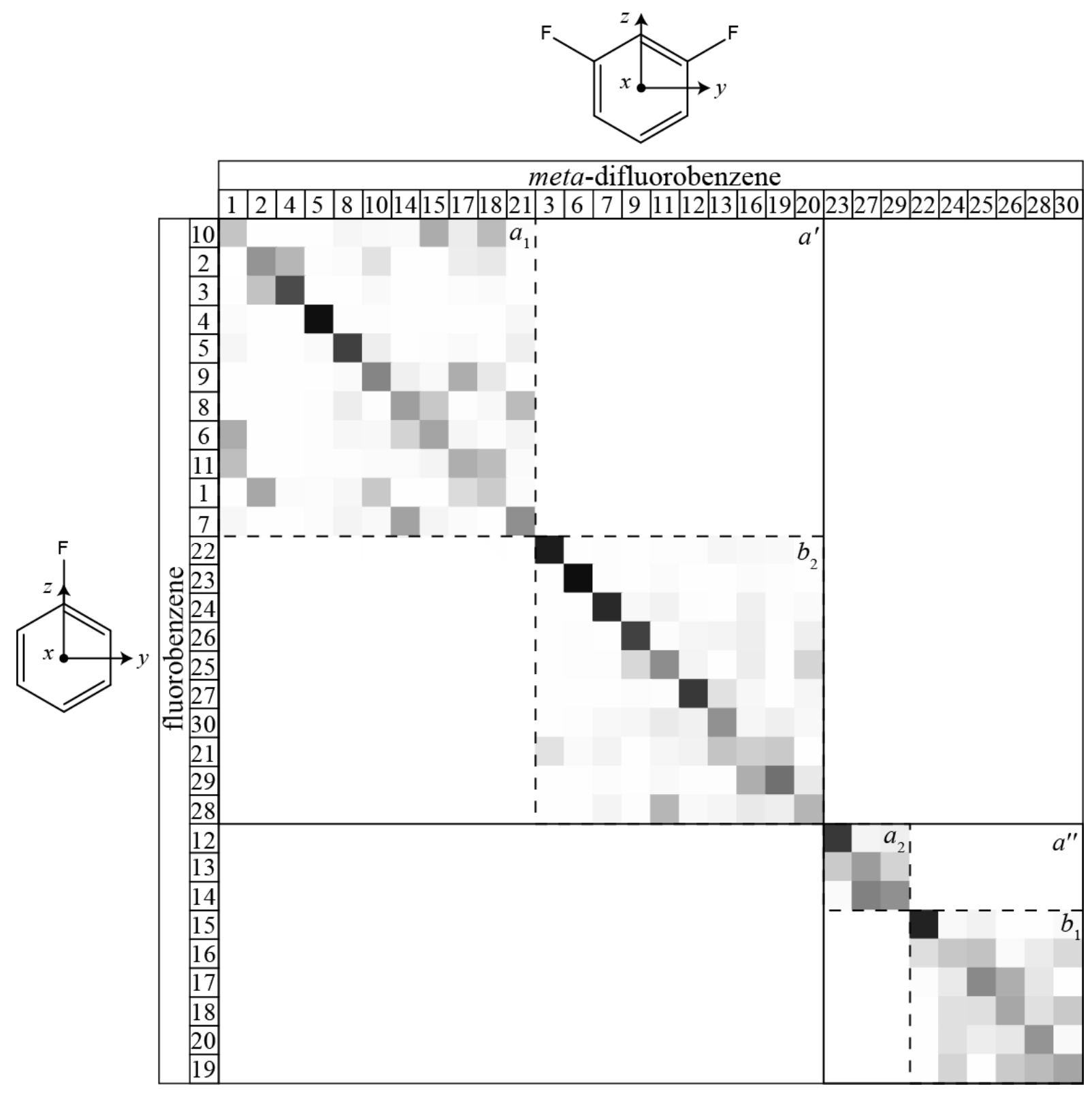


Figure 3
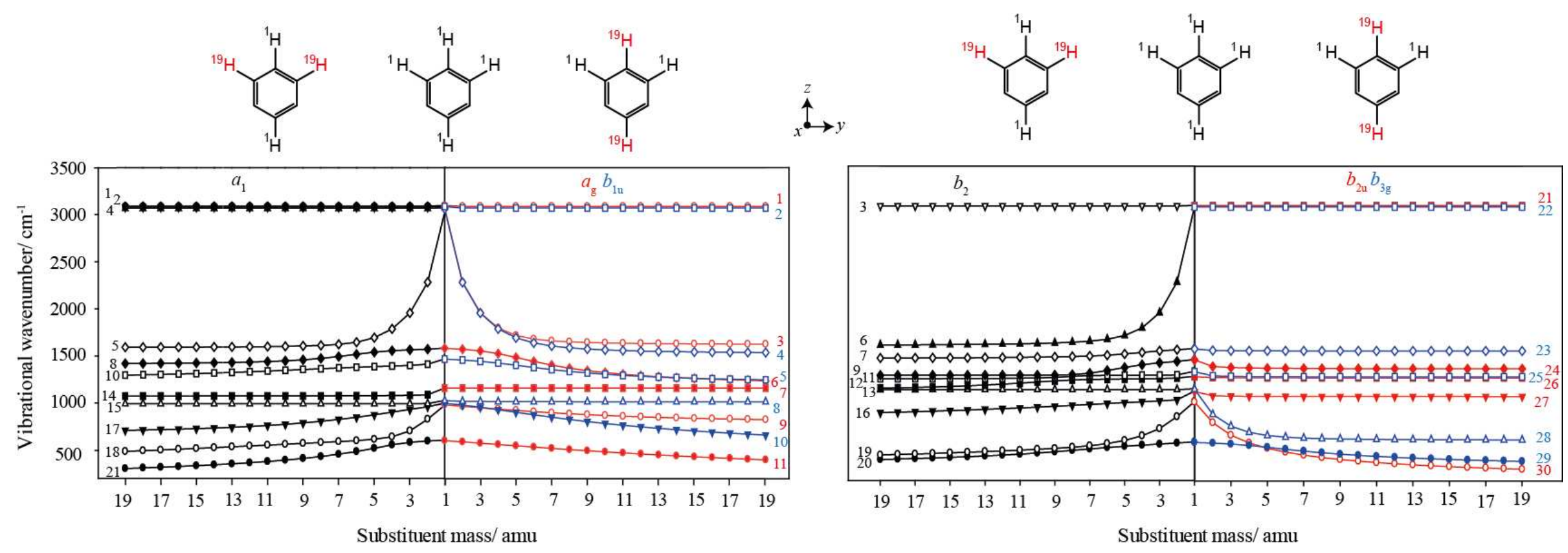


\section{Figure 4}
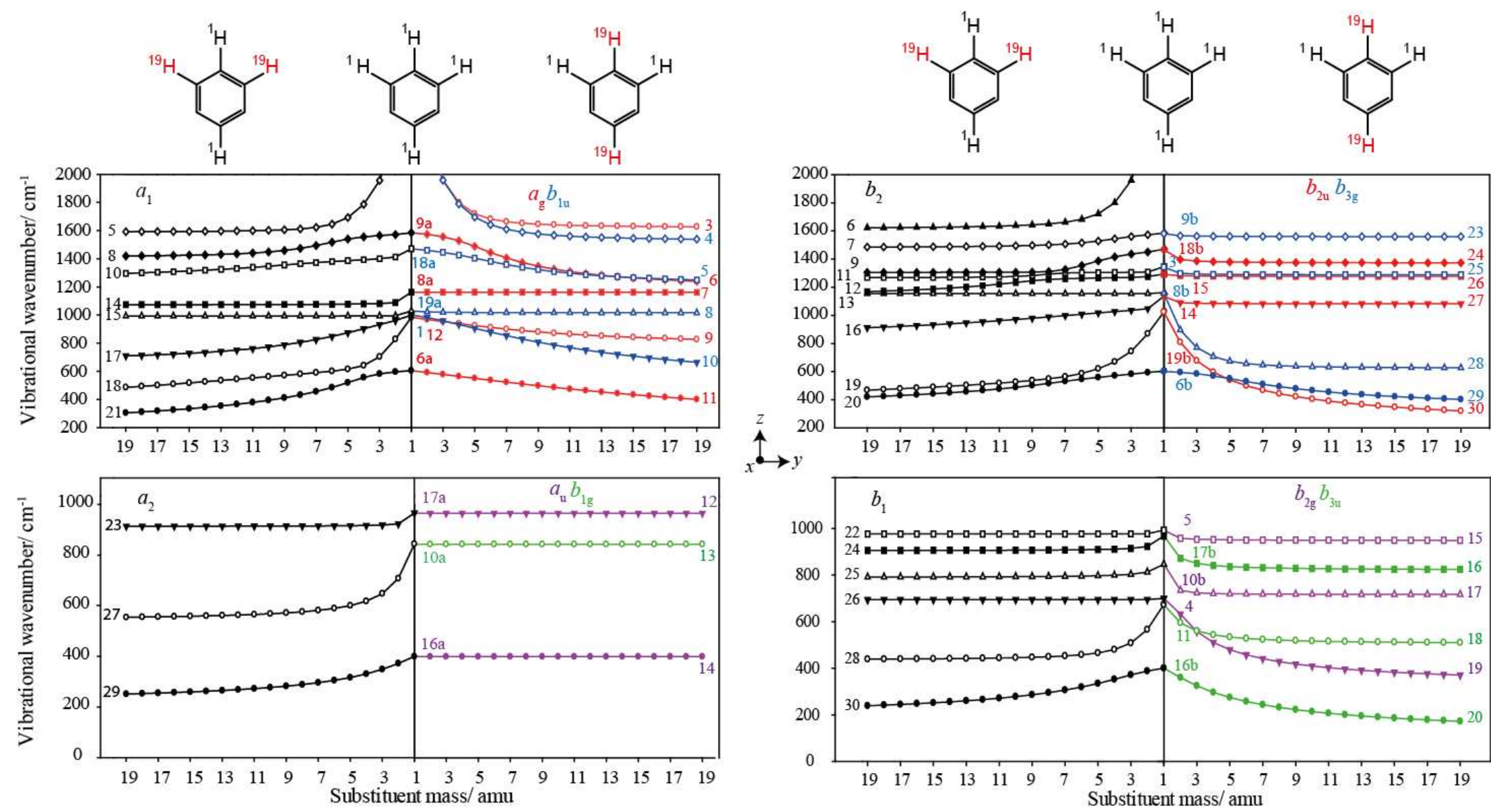


\section{Figure 5}

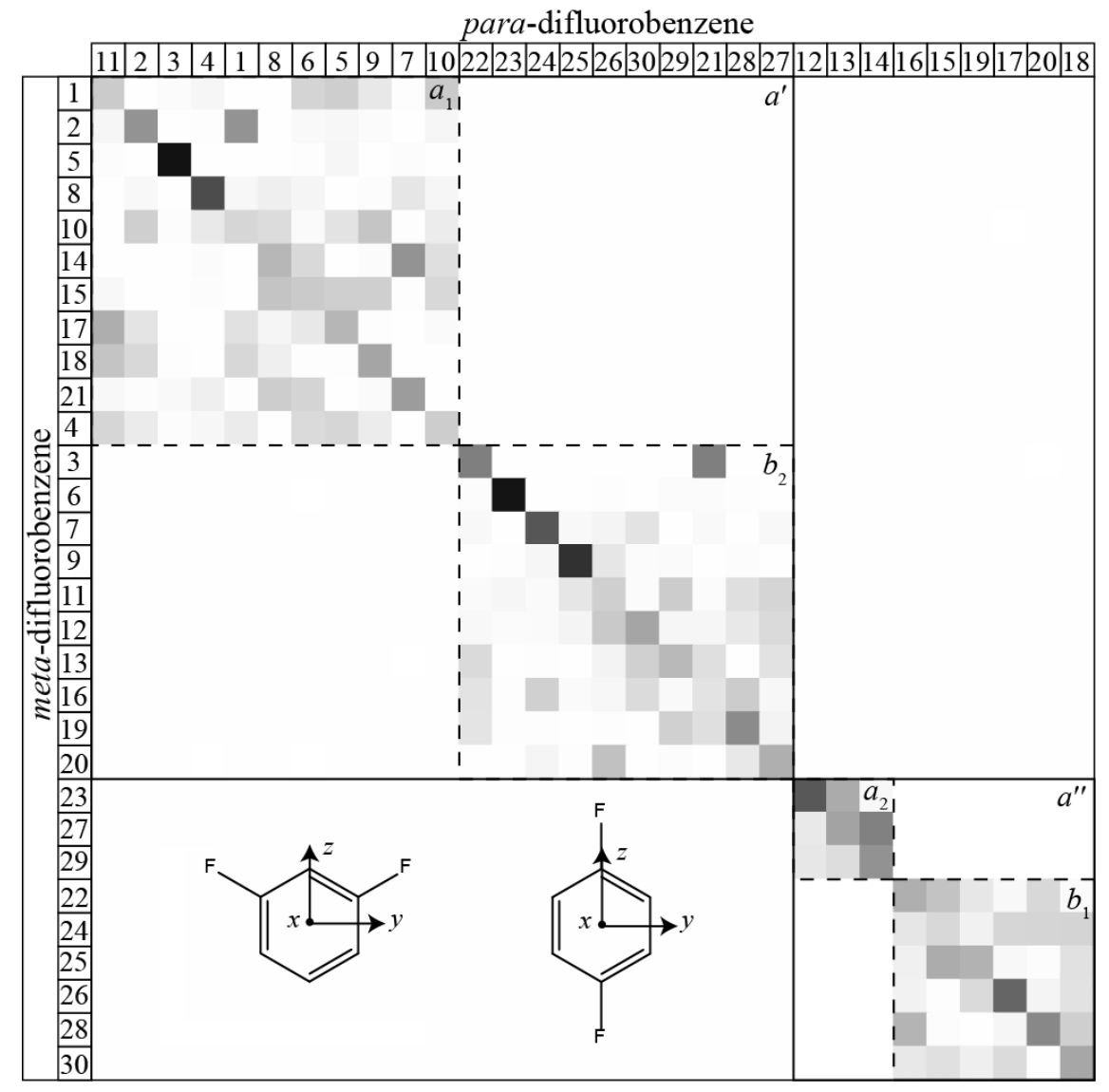


Figure 6
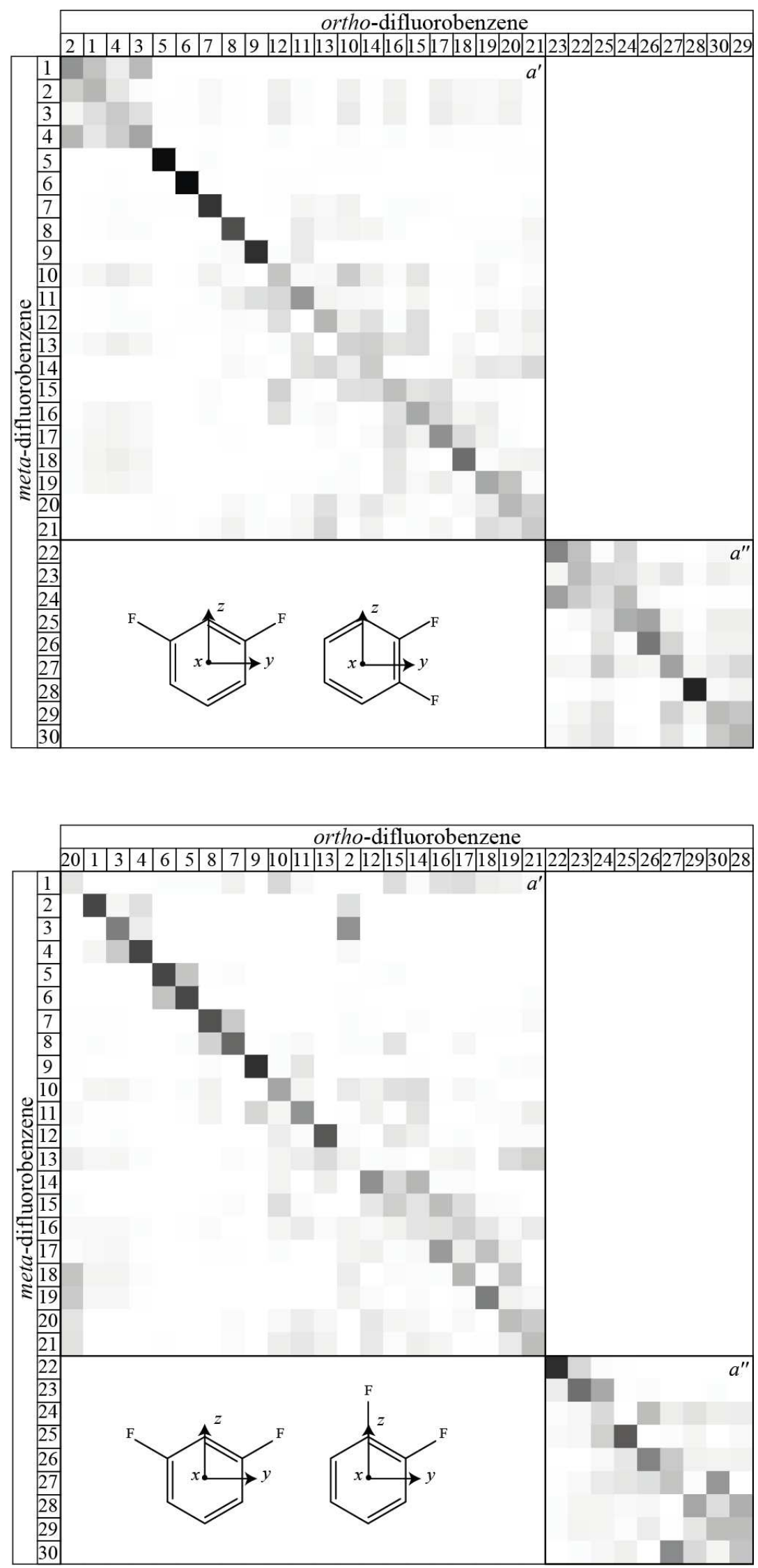
Figure 7
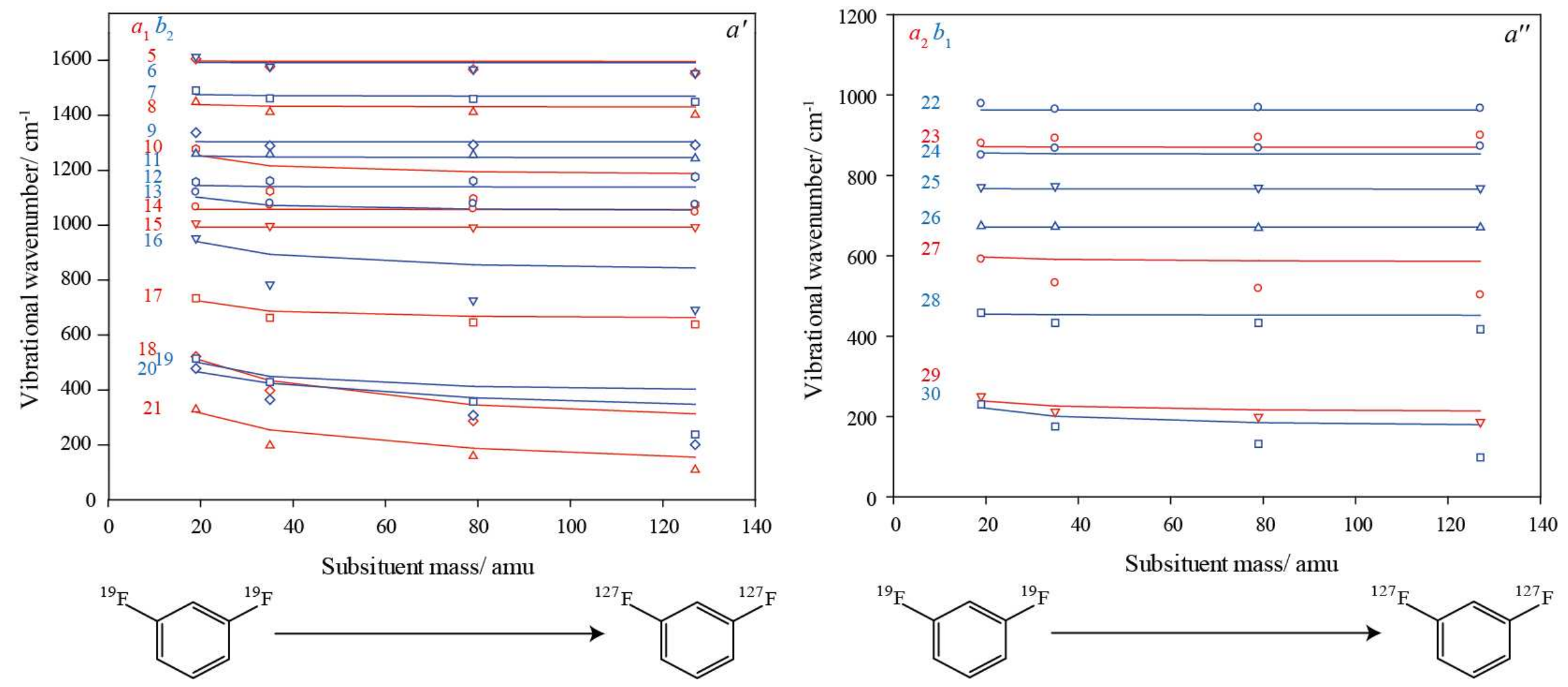


\section{Figure 8}
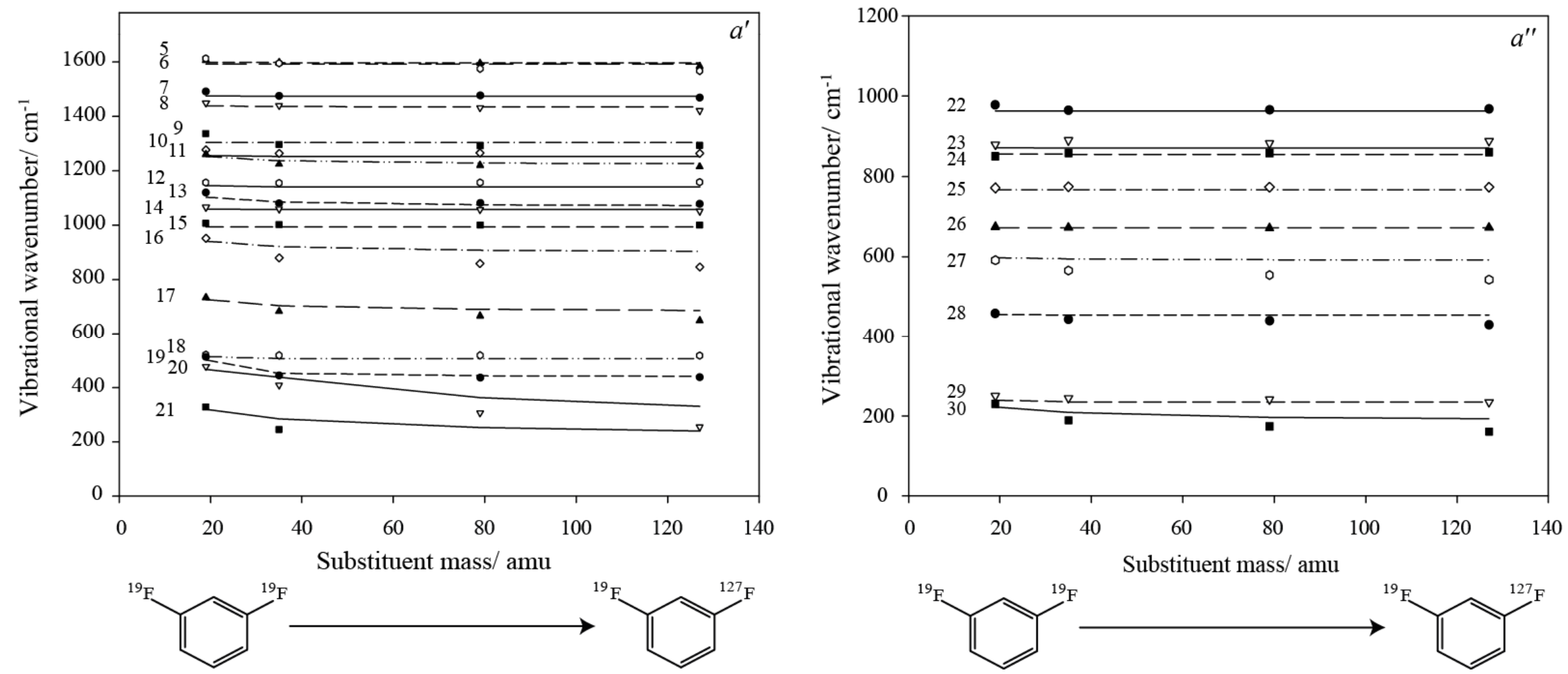


\section{Figure 9}

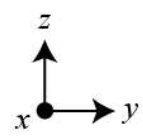

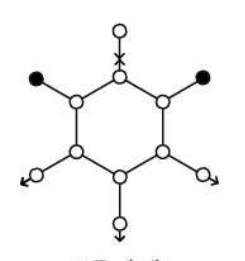

${ }^{m} D_{1}\left(a^{\prime}\right)$

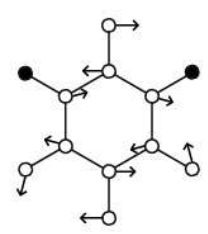

${ }^{m} D_{6}\left(a^{\prime}\right)$
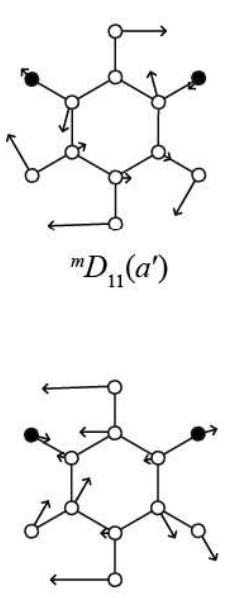

${ }^{m} D_{16}\left(a^{\prime}\right)$

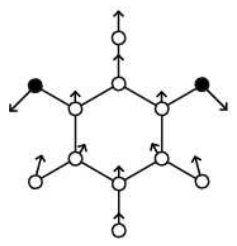

${ }^{m} D_{21}\left(a^{\prime}\right)$

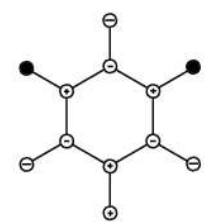

${ }^{m} D_{26}\left(a^{\prime \prime}\right)$

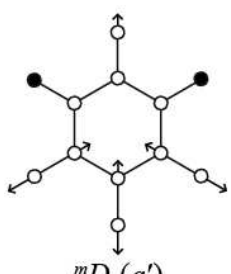

${ }^{m} D_{2}\left(a^{\prime}\right)$

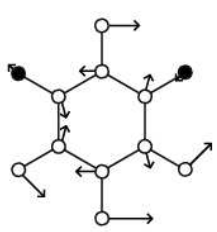

${ }^{m} D_{7}\left(a^{\prime}\right)$
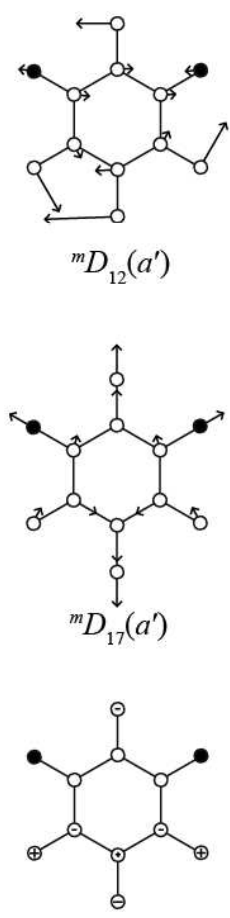

${ }^{m} D_{22}\left(a^{\prime \prime}\right)$

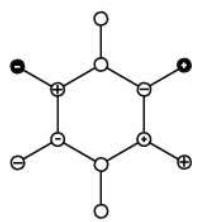

${ }^{m} D_{27}\left(a^{\prime \prime}\right)$

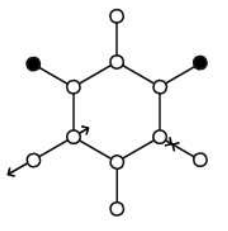

${ }^{m} D_{3}\left(a^{\prime}\right)$

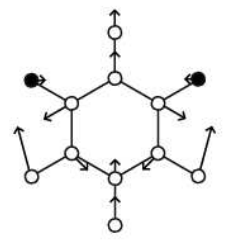

${ }^{m} D_{8}\left(a^{\prime}\right)$

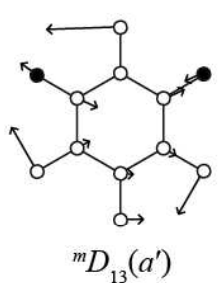

${ }^{m} D_{13}\left(a^{\prime}\right)$
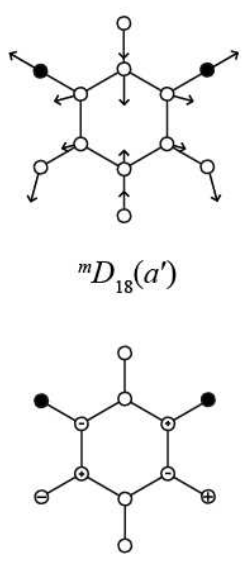

${ }^{m} D_{23}\left(a^{\prime \prime}\right)$

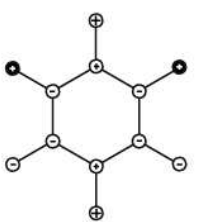

${ }^{m} D_{28}\left(a^{\prime \prime}\right)$

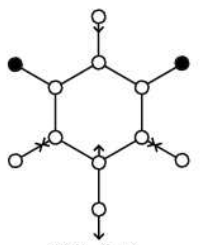

${ }^{m} D_{4}\left(a^{\prime}\right)$

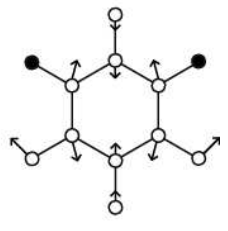

${ }^{m} D_{5}\left(a^{\prime}\right)$

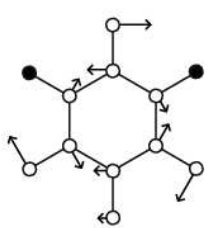

${ }^{m} D_{9}\left(a^{\prime}\right)$

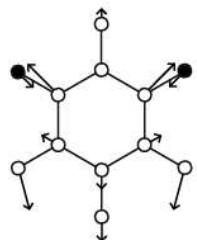

${ }^{m} D_{10}\left(a^{\prime}\right)$
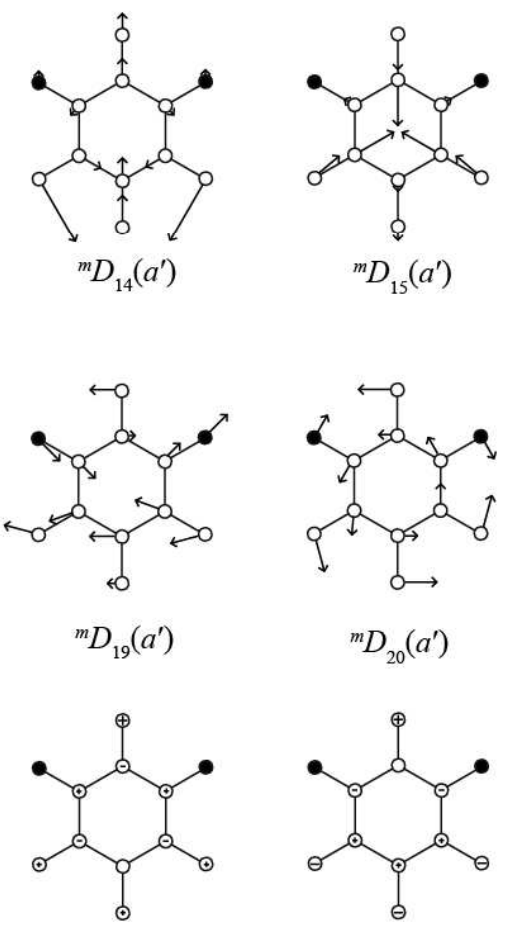

${ }^{m} D_{24}(a ")$

${ }^{m} D_{25}\left(a^{\prime \prime}\right)$
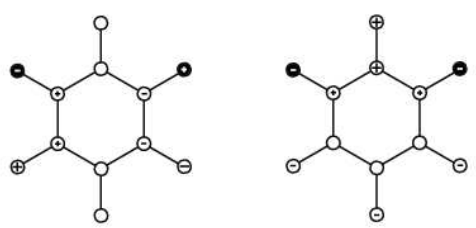

${ }^{m} D_{29}\left(a^{\prime \prime}\right)$ 
Figure 10

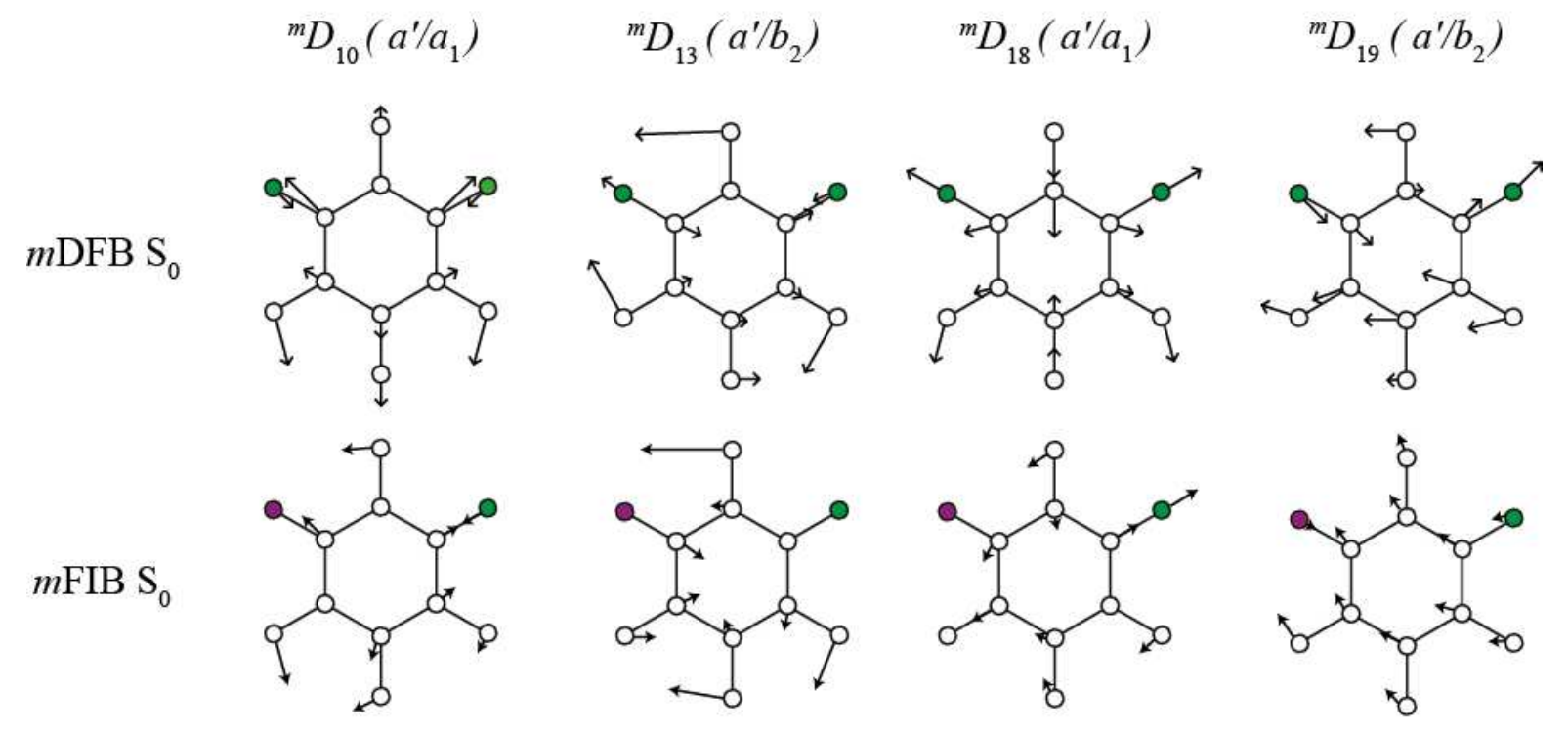




\section{References}

${ }^{1}$ E. B. Wilson, Jr, Phys. Rev. 45 (1934) 706.

${ }^{3}$ G. Varsányi, Assignments of the Vibrational Spectra of Seven Hundred Benzene Derivatives (Wiley, New York, 1974).

${ }^{3}$ R. S. Mulliken, J. Chem. Phys. 23 (1955) 1997.

${ }^{4}$ G. Herzberg, Molecular Spectra and Molecular Structure II: Infrared and Raman Spectra of Polyatomic Molecules (Krieger, Malabar, 1991), p.272.

${ }^{5}$ A. M. Gardner and T. G. Wright. J. Chem. Phys. 135 (2011) 114305.

${ }^{6}$ A. Andrejeva, A. M. Gardner, W. D. Tuttle, and T. G. Wright, J. Molec. Spectrosc. 321 (2016) 28.

${ }^{7}$ W. D. Tuttle, A. M. Gardner, A. Andrejeva, D. J. Kemp, J. C. A. Wakefield and T. G. Wright, J. Molec. Spectrosc. 344 (2018) 46.

${ }^{8}$ J. P. Harris, A. Andrejeva, W. D. Tuttle, I. Pugliesi, C. Schriever, and T. G. Wright, J. Chem. Phys. 141 (2014) 244315.

${ }^{9}$ A. Andrejeva, W. D. Tuttle, J. P. Harris, and T. G. Wright, J. Chem. Phys. 143 (2015) 104312.

${ }^{10}$ A. Andrejeva, W. D. Tuttle, J. P. Harris, and T. G. Wright, J. Chem. Phys. 143 (2015) 244320.

${ }^{11}$ A. M. Gardner, A. M. Green, V M. Tamé-Reyes, V. H. K. Wilton and T. G. Wright

J. Chem. Phys. 138 (2013) 134303.

${ }^{12}$ A. M. Gardner, A. M. Green, V. M. Tamé-Reyes, K. L. Reid, J. A. Davies, V. H. K. Parkes and T. G. Wright J. Chem. Phys. 140 (2014) 114038.

${ }^{13}$ J. R. Gascooke and W. D. Lawrance, J. Chem. Phys., 138 (2013) 134302.

${ }^{14}$ A. M Gardner, W. D. Tuttle, L. Whalley, A. Claydon, J. H. Carter, and T G. Wright, J. Chem. Phys. 145 (2016) 124307.

${ }^{15}$ W. D. Tuttle, A. M. Gardner, L. E. Whalley and T. G. Wright, J. Chem. Phys. 146 (2017) 244310.

${ }^{16}$ W. D. Tuttle, A. M Gardner, K. B. O’Regan, W. Malewicz, and T. G. Wright, J. Chem. Phys. 146 (2017) 124309.

${ }^{17}$ A. M. Gardner, W. D. Tuttle, P. Groner, and T. G. Wright, J. Chem. Phys. 146 (2017) 124308.

${ }^{18}$ W. D. Tuttle, A. M. Gardner, and T. G. Wright, Chem. Phys. Lett. 684 (2017) 339. 
${ }^{19}$ Gaussian 09, Revision E.01, M. J. Frisch, G. W. Trucks, H. B. Schlegel, G. E. Scuseria, M. A. Robb, J. R. Cheeseman, G. Scalmani, V. Barone, B. Mennucci, G. A. Petersson, H. Nakatsuji, M. Caricato, X. Li, H. P. Hratchian, A. F. Izmaylov, J. Bloino, G. Zheng, J. L. Sonnenberg, M. Hada, M. Ehara, K. Toyota, R. Fukuda, J. Hasegawa, M. Ishida, T. Nakajima, Y. Honda, O. Kitao, H. Nakai, T. Vreven, J. A. Montgomery, Jr., J. E. Peralta, F. Ogliaro, M. Bearpark, J. J. Heyd, E. Brothers, K. N. Kudin, V. N. Staroverov, R. Kobayashi, J. Normand, K. Raghavachari, A. Rendell, J. C. Burant, S. S. Iyengar, J. Tomasi, M. Cossi, N. Rega, J. M. Millam, M. Klene, J. E. Knox, J. B. Cross, V. Bakken, C. Adamo, J. Jaramillo, R. Gomperts, R. E. Stratmann, O. Yazyev, A. J. Austin, R. Cammi, C. Pomelli, J. W. Ochterski, R. L. Martin, K. Morokuma, V. G. Zakrzewski, G. A. Voth, P. Salvador, J. J. Dannenberg, S. Dapprich, A. D. Daniels, Ö. Farkas, J. B. Foresman, J. V. Ortiz, J. Cioslowski, and D. J. Fox, Gaussian, Inc., Wallingford CT, 2009.

${ }^{20}$ I. Pugliesi and K. Muller-Dethlefs, J. Phys. Chem. A 110 (2006) 4657. A free download of the software can be found at http://www.fclab2.net

${ }^{21}$ J. H. S. Green, Spectrochim. Acta. 26A (1970) 1523.

${ }^{22}$ J. H. S. Green, W. Kynaston and H. M. Paisley, J. Chem. Soc. 473 (1963).

${ }^{23}$ E. E. Ferguson, R. L. Collins, J. R. Nielsen and D. C. Smith, J. Chem. Phys. 21, 1470 (1953)

${ }^{24}$ G. A. Crowder amd D. W. Scott, J. Chem. Phys. 21, 1470 (1953)

${ }^{25}$ E. Herz, Monatsch. 74, 160 (1942)

${ }^{26}$ J. R. Scherer and J. C. Evans, Spectrochim. Acta 19, 1754 (1963).

${ }^{27}$ K. W. F Kohlrausch and G. P. Ypsilanti, Monatsch. 66, 285 (1935)

${ }^{28}$ P. A. Graham and S. H. Kable, J. Chem. Phys. 103, 15 (1995).

${ }^{29}$ H. W. Wilson, Spectrochim. Acta 30A (1974) 2141.

${ }^{30}$ S. A. Kudchadker, A. P. Kudchadker, R. C. Wilhoit and B. J. Zwolinski, Thermochim. Acta 30 (1979) 319.

${ }^{31}$ A. Hidalogo and C. Otero. Spectrochim. Acta 16 (1960) 528.

${ }^{32}$ K. S. Pitzer and D. W. Scott, J. Am. Chem. Soc. 65, 803 (1943).

${ }^{33}$ J.K. Wilmshurst and H. S. Bernstein, Can. J. Chem. 35, 911 (1957)

${ }^{34}$ C. Garrigou-Lagrange, M. Chehata and J. Lascombe, J. Chim. Phys. 63, 552 (1966). 
${ }^{35}$ J. I. Selco and P. G. Carrick. J. Mol. Spec. 173, 262 (1995)

${ }^{36}$ K. W. F Kohlrausch and A. Pongratz, Monatsch. 65, 199 (1935)

${ }^{37}$ J. H. S. Green, D. J. Harrison and W. Kynaston. Spectrochim. Acta 27A (1971) 2199. 